\title{
Occupational exposure and challenges in tackling M. bovis at human-animal interface: a narrative review
}

\author{
K. Renuga Devi ${ }^{1}$ L. J. Lee ${ }^{2}$ Lee Tze Yan ${ }^{3} \cdot$ Amin-Nordin Syafinaz $^{4} \cdot$ I. Rosnah ${ }^{1} \cdot$ V. K. Chin ${ }^{4,5}$
}

Received: 11 July 2020 / Accepted: 12 January 2021 / Published online: 16 March 2021

(c) The Author(s), under exclusive licence to Springer-Verlag GmbH, DE part of Springer Nature 2021

\begin{abstract}
Zoonotic tuberculosis caused by Mycobacterium bovis (M. bovis), a member of Mycobacterium tuberculosis complex (MTBC) has increasingly gathered attention as a public health risk, particularly in developing countries with higher disease prevalence. M. bovis is capable of infecting multiple hosts encompassing a number of domestic animals, in particular cattle as well as a broad range of wildlife reservoirs. Humans are the incidental hosts of $M$. bovis whereby its transmission to humans is primarily through the consumption of cattle products such as unpasteurized milk or raw meat products that have been contaminated with M. bovis or the transmission could be due to close contact with infected cattle. Also, the transmission could occur through aerosol inhalation of infective droplets or infected body fluids or tissues in the presence of wound from infected animals. The zoonotic risk of $M$. bovis in humans exemplified by miscellaneous studies across different countries suggested the risk of occupational exposure towards $M$. bovis infection, especially those animal handlers that have close and unreserved contact with cattle and wildlife populations These animal handlers comprising of livestock farmers, abattoir workers, veterinarians and their assistants, hunters, wildlife workers as well as other animal handlers are at different risk of contracting M. bovis infection, depending on the nature of their jobs and how close is their interaction with infected animals. It is crucial to identify the underlying transmission risk factors and probable transmission pathways involved in the zoonotic transmission of M. bovis from animals to humans for better designation and development of specific preventive measures and guidelines that could reduce the risk of transmission and to protect these different occupational-related/populations at risk. Effective control and disease management of zoonotic tuberculosis caused by M. bovis in humans are also hindered by various challenges and factors involved at animal-human interface. A closer look into factors affecting proper disease control and management of $M$. bovis are therefore warranted. Hence, in this narrative review, we have gathered a number of different studies to highlight the risk of occupational exposure to M. bovis infection and addressed the limitations and challenges underlying this context. This review also shed lights on various components and approaches in tackling M. bovis infection at animal-human interface.
\end{abstract}

Keywords M. bovis · Zoonotic tuberculosis · Occupational exposure · Bovine tuberculosis · Animal-human interface Disease control and management

V. K. Chin

cvk717@gmail.com

1 Department of Community Health, Faculty of Medicine, Universiti Kebangsaan Malaysia, Jalan Yaacob Latiff, Bandar Tun Razak, 56000 Kuala Lumpur, Malaysia

2 Prima Nexus Sdn. Bhd, Menara CIMB, Jalan Stesen Sentral 2, Kuala Lumpur, Malaysia

3 Perdana University School of Liberal Arts, Science and Technology (PUScLST), Suite 9.2, 9th Floor, Wisma
Chase Perdana, Changkat Semantan Damansara Heights, 50490 Kuala Lumpur, Malaysia

4 Department of Medical Microbiology, Faculty of Medicine and Health Sciences, Universiti Putra Malaysia, 43400 UPM Serdang, Selangor, Malaysia

5 Integrative Pharmacogenomics Institute (iPROMISE), Universiti Teknologi MARA, Puncak Alam Campus, Bandar, 42300 Puncak Alam, Selangor, Malaysia 


\section{Introduction}

Zoonotic tuberculosis (zTB) caused by Mycobacterium bovis (M. bovis), a member of Mycobacterium tuberculosis complex is considered as a serious public health threat in low- and middle-income/developing countries and resulted in economic losses and trade barriers with a huge impact on the livehoods of marginalized and poor communities (Cosivi et al. 1998; Jagielski et al. 2016; WHO 2016). In 2016, there is about 147,000 new cases of zoonotic tuberculosis with 12,500 deaths reported globally, which constitutes approximately $1.4 \%$ of the tuberculosis burden worldwide. The African regions are heavily affected with zoonotic tuberculosis followed by Southeast Asian countries (WHO 2016). Nonetheless, the true incidence of zoonotic tuberculosis in humans could probably be underestimated due to poor surveillance system in most countries, under-reporting and diagnosis challenges in accurately differentiating $M$. bovis from M. tuberculosis (WHO 2016). Despite these challenges, M. bovis has been well recognized to infect cattle and humans with higher prevalence of the disease incidence occurred in developing countries (Müller et al. 2013; OIE 2015). This has undoubtedly made bovine tuberculosis a truly global public health threat (Cosivi et al. 1998; Müller et al. 2013; OIE 2019).

Humans acquired $M$. bovis infection primarily through the consumption of unpasteurized milk and dairy products contaminated with $M$. bovis or via close contact with cattle infected with $M$. bovis. The transmission may occur through eating contaminated cattle meats, inhalation of infectious droplets exhaled by humans or animals or has direct contact with the infected animals through the presence of a wound (de la Rua-Domenech 2006; Thoen et al. 2010). M. bovis has a wide range of susceptible hosts to infect, which include both domestic and wildlife animals. Cattle, cervids and buffalo are a few of the examples of maintenance hosts for M. bovis whereas goats, dogs, sheep, horses, camels, wild ruminants and others are considered as spill-over hosts. Wild animal and predatory felines including lions, tigers, leopards and lynx are also susceptible to the infection (CSFPH 2009). Therefore, it remains a challenging task to control and eradicate bovine tuberculosis due to its multi-hosts characteristic.

Strict hygiene controls in livestock management and milk pasteurization have indisputably reduced zonootic tuberculosis transmission in developed countries. Nevertheless, the threat of $M$. bovis infection is still ongoing, at least in developing countries and in specific occupational groups/populations working closely with domestic and wildlife animals (Vayr et al. 2018). Populations that are at a heightened risk of contracting $M$. bovis infection include livestock farmers, abattoir workers, animal husbandry workers, HIV-positive persons, veterinary personnel, butchers, hunter, wildlife workers and live market workers (Haagsma et al. 2012; Vayr et al. 2018). Further, populations holding the practice of raw milk consumption (Silva et al. 2018) and pastoralist communities in SubSaharan African maintaining close contact with livestock and regularly keeping livestock inside their house are also susceptible to M. bovis infection (Duguma et al. 2017). Nevertheless, current data documenting the risk of occupational exposure to $M$. bovis infection are limited. Most of the studies are confined to small-scale studies and/or based on retrospective data review (Cordova et al. 2012; Haagsma et al. 2012). Also, it is critical to identify the underlying risk factors and pathways associated with the transmission of $M$. bovis to the occupational-related workers/populations at risk to aid in the development and implementation of specific preventive measures and guideline that are tailored to the different level risk of occupational exposure to M. bovis infection (Vayr et al. 2018).

In line with the global effort to stop the tuberculosis pandemic, it is imperative to capture the real burden of zoonotic tuberculosis particularly in low- and middle-income countries as these countries may have minimal to no cattle-control programme. Apart from that, current disease control and management on human tuberculosis is focusing on humanto-human transmission caused by M. tuberculosis. This in turn will have minimal impact on the control and prevention of zoonotic tuberculosis where disease transmission is predominantly through animal handling and food ingestion. Therefore, it is believed that zoonotic tuberculosis will become a more critical public health problem, at least in developing countries (Cousins 2001; Wedlock et al. 2002, 2012; Luciano and Roess 2020). Identification of key challenges involved at human-animal interface will facilitate better disease control and management. On the other side, "Roadmap for Zoonotic Tuberculosis" has been introduced in 2017 with the emphasis on zoonotic tuberculosis caused by $M$. bovis in humans and bovine tuberculosis caused by $M$. bovis in animals. The roadmap has prioritized on ten areas and three core themes with the hope to end the global tuberculosis epidemic by 2030 . One of the ten priority areas proposed is to reduce the risk of zoonotic tuberculosis transmission to humans by identifying the populations at risk and the key transmission pathways responsible for zoonotic transmission. The roadmap also highlighted the need to define populations at risk of infection, including people with risk of occupational exposure (OIE, WHO, and FAO 2017). A closer look into the association between occupational exposure and $M$. bovis infection are then needed. Therefore, in this narrative review, we seek to highlight the risk of occupational exposure to M. bovis infection and the associated challenges involved with the support from previous 
literature. This review also discusses the challenges and provides some useful windows in tackling $M$. bovis infection at animal-human interface.

\section{Risk of occupational exposure and Mycobacterium bovis infection}

\section{Overview}

A retrospective study of 39 patients with confirmed M. bovis infection between 1996 and 2008 highlighted that occupational exposure is one of the most prominent risk factors in zoonotic transmission of $M$. bovis infection besides other risk factors including history of living in rural area and consumption of unpasteurized milk (Cordova et al. 2012). Another retrospective study also related the risk of $M$. bovis infection to occupational exposure and exposure to regions that are endemic for bovine tuberculosis (Rodríguez et al. 2009). On the other hand, Baker et al. (2006) had associated the occupational risk of $M$. bovis infection with livestock farming (owners or workers), being an abattoir worker or veterinary receptionist and drinking unpasteurized milk (Baker et al. 2006). These aforementioned studies have undoubtedly suggested a link between occupational exposure and $M$. bovis infection. We have performed a literature search using different keywords such as " $M$. bovis and occupational exposure", "population and M. bovis", "animals and M. bovis" "wildlife and M. bovis", "M. bovis and humans", "M. bovis", "zoonotic tuberculosis" and "bovine tuberculosis" through PubMed, Scopus and Google Scholar database to identify the risk of occupational exposure to M. bovis infection. This section gathered the evidences on the risk of occupational exposure to M. bovis infection. However, the information inferred is based on selected studies which subjected to publication bias and will affect the strength of evidence across this body of literature. Table 1 depicts the major findings and limitations of selected published studies related to risk of occupational exposure and M. bovis infection.

\section{Occupational risk groups and $M$. bovis infection}

A study by Torres-Gonzalez and his colleagues (2013) classified occupational groups at risk into three major groupings (high, medium and low exposure) in accordance to the types of activity and the conditions and duration of exposure to cattle. In the study, the high exposure group refers to workers who have direct contact with livestock in closed spaces, such as abattoir workers, foremen, veterinary personnel conducting cattle necropsies and milkers. Medium risk group workers include herders, tractor operators, feeders, maintenance technicians, household contacts living in cowsheds and other veterinary personnel who have direct contact with livestock in open spaces. As for low-risk group workers, they include administrative clerks, individuals involved in commercial activities and cowshed owners who are presumably to have no direct contact with livestock (Torres-Gonzalez et al. 2013). On the other hand, Deffontaines et al. (2019) categorized occupational risk groups into livestock farmers and farm workers (mostly cattle), slaughterhouse workers, and individuals who monitor the health status of wild animals and hunters. The classification is based on the current rise of incidence of animal disease and the heightened risk of exposed to animals infected with M. bovis. Other occupational risk groups that are not included in the guidelines for monitoring employees after being exposed to bovine tuberculosis include service providers to farm, knackery workers, laboratory workers and wildlife park, zoo and animal house workers due to their potential risk of contracting bovine tuberculosis (Deffontaines et al. 2013).

\section{Livestock farmers}

A plethora of studies have demonstrated the risk of occupational exposure with $M$. bovis infection in livestock farming, especially those who are living or working closely with cattle (Cleaveland et al. 2007; Oloya et al. 2008; Tigre et al. 2011; Adesokan et al. 2012; Gumi et al. 2012; Torres-Gonzalez et al. 2013; Lombardi et al. 2017; Nuru et al. 2017; Kemal et al. 2019). For instance, Torres-Gonzalez (2013) reported that the overall prevalence of latent tuberculosis infection (LTBI) in 311 abattoir and dairy farm laborers and their household contacts in Mexico are 76.2 and $58.5 \%$ by tuberculin skin test (TST) and interferon-gamma release assay (IGRA), respectively. Further, the study demonstrated that the prevalence of LTBI and pulmonary tuberculosis among livestock workers are higher in comparison to other populations in Mexico and is robustly associated with occupational exposure. Also, the prevalence of symptomatic bovine tuberculosis is presumably higher in the population of livestock workers compared to general population. These findings clearly suggest a link between $M$. bovis and occupational exposure (Torres-Gonzalez et al. 2013). In North-Western Ethiopia, Nuru et al. (2017) reported that 40 culture samples from 70 human TB lymphadenitis (TBLN) cases are tested positive for tuberculosis, with two isolates being identified as $M$. bovis through spoligotyping analysis, suggesting the possible zoonotic transmission of $M$. bovis to humans. However, further investigations are warranted on the probable transmission pathways since the evidence on direct transmission of $M$. bovis from cattle to humans is lacking (Nuru et al. 2017). The direct transmission of $M$. bovis from infected cattle to livestock farmers and/or livestock owners evident by numerous studies highlighting the occupational risk to M. bovis infection (Oloya et al. 2008; 


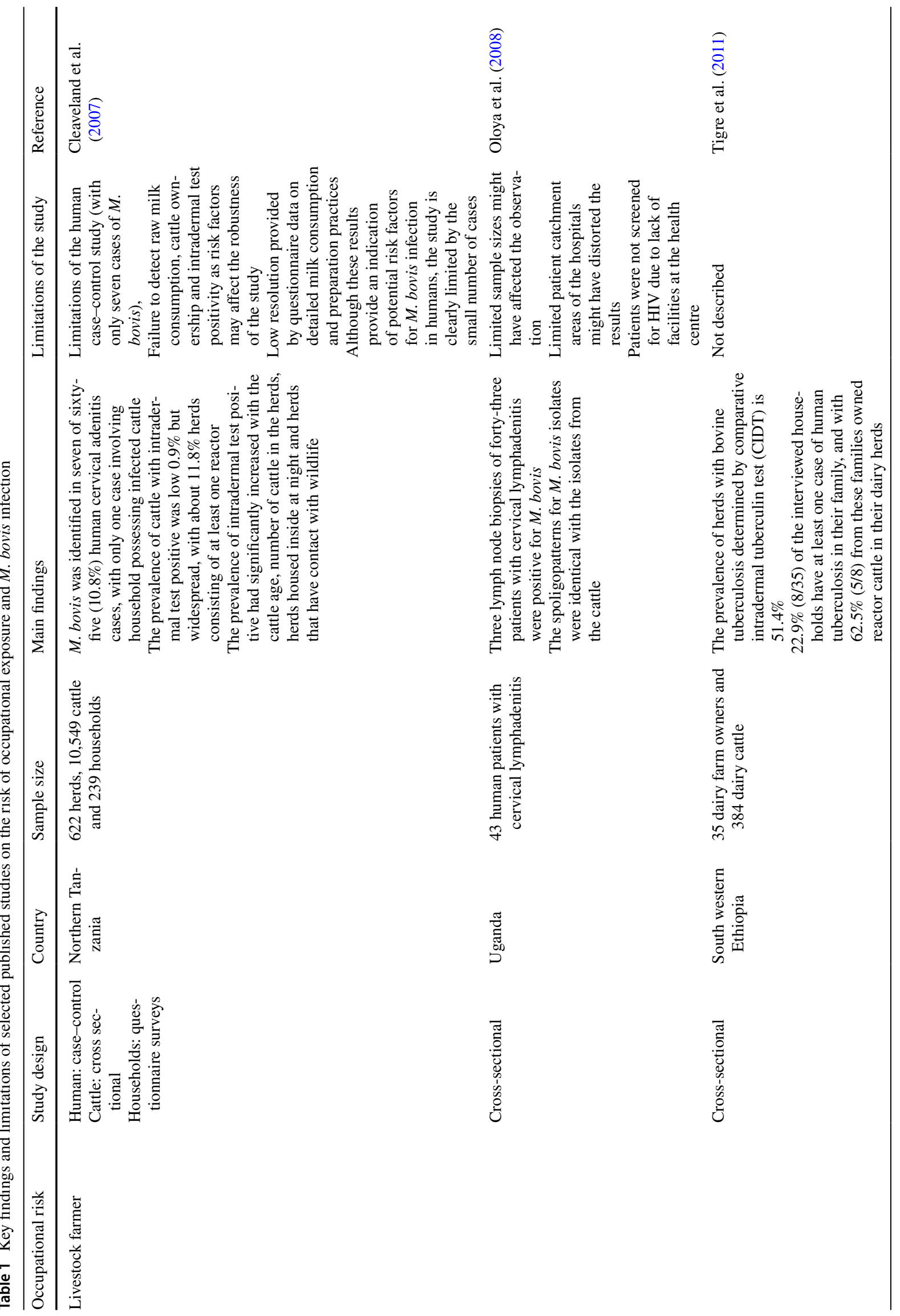




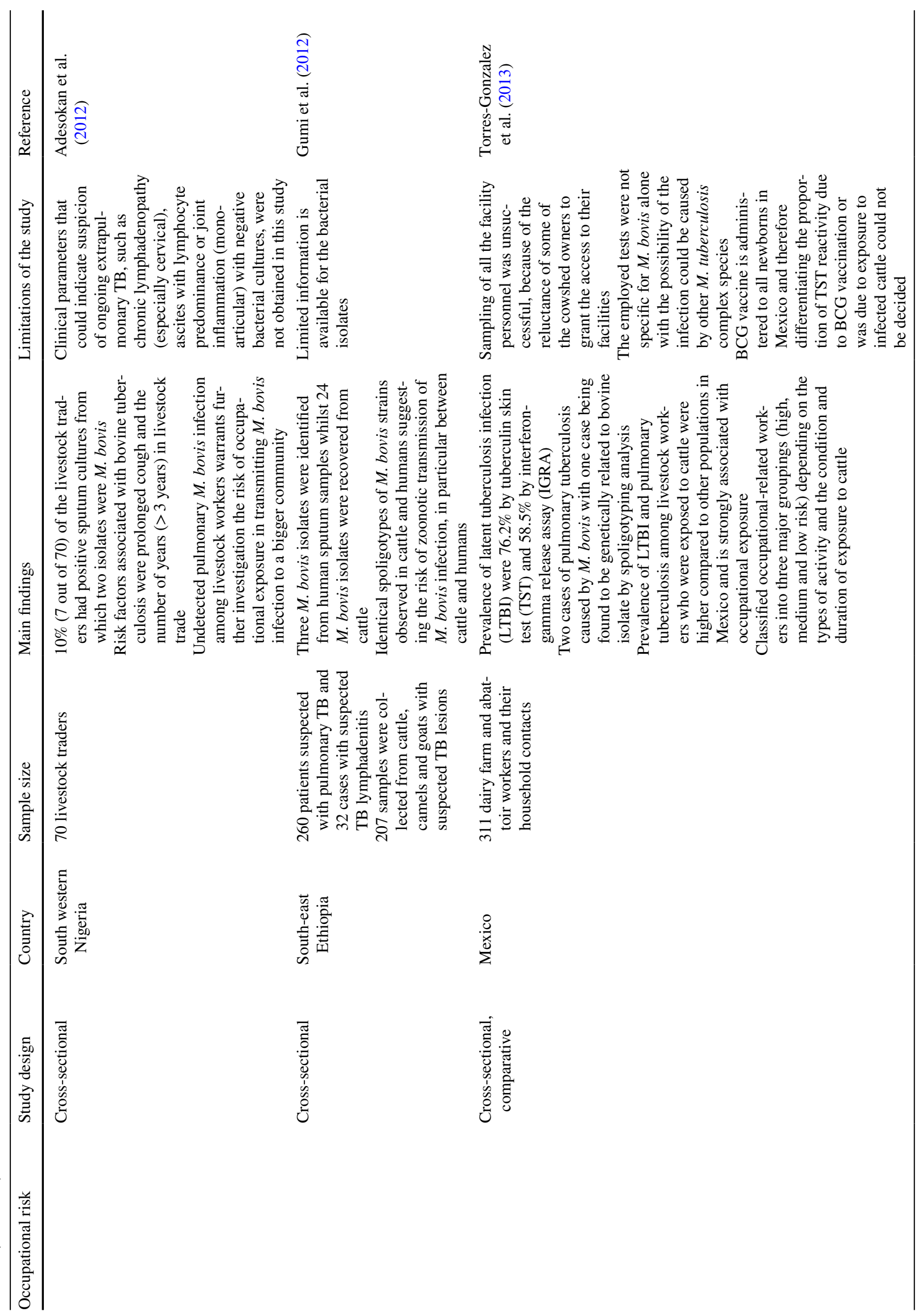




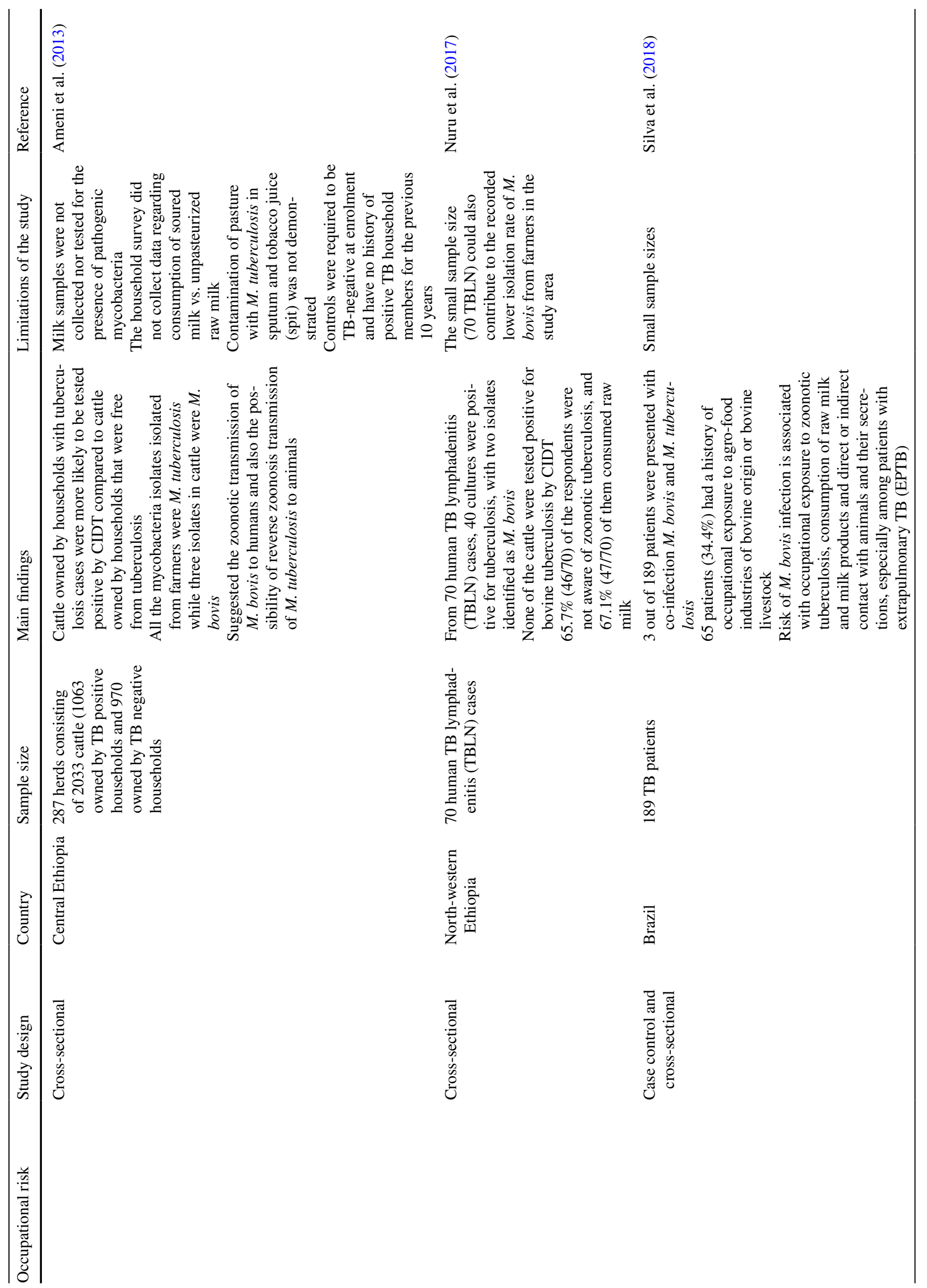




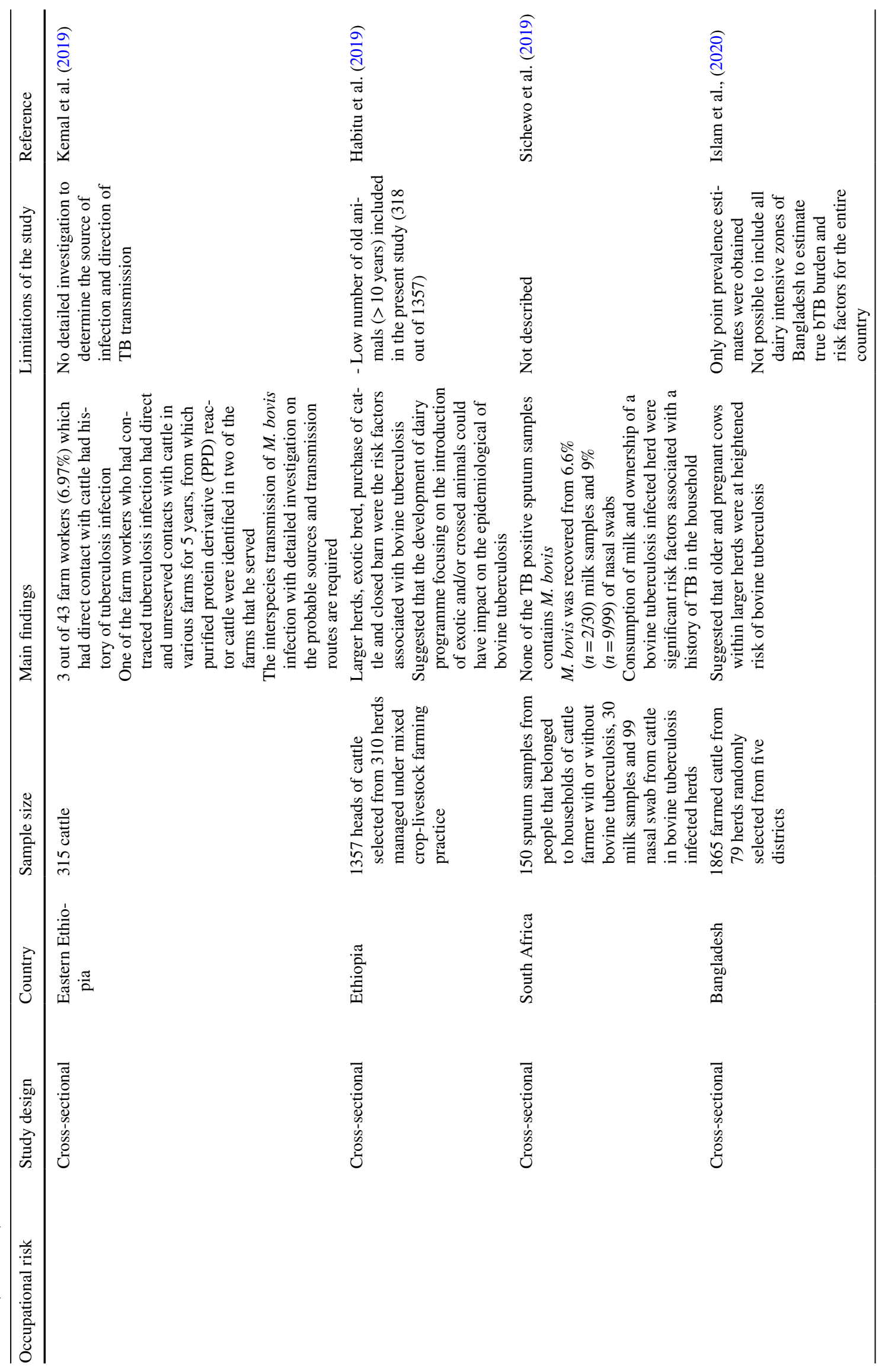




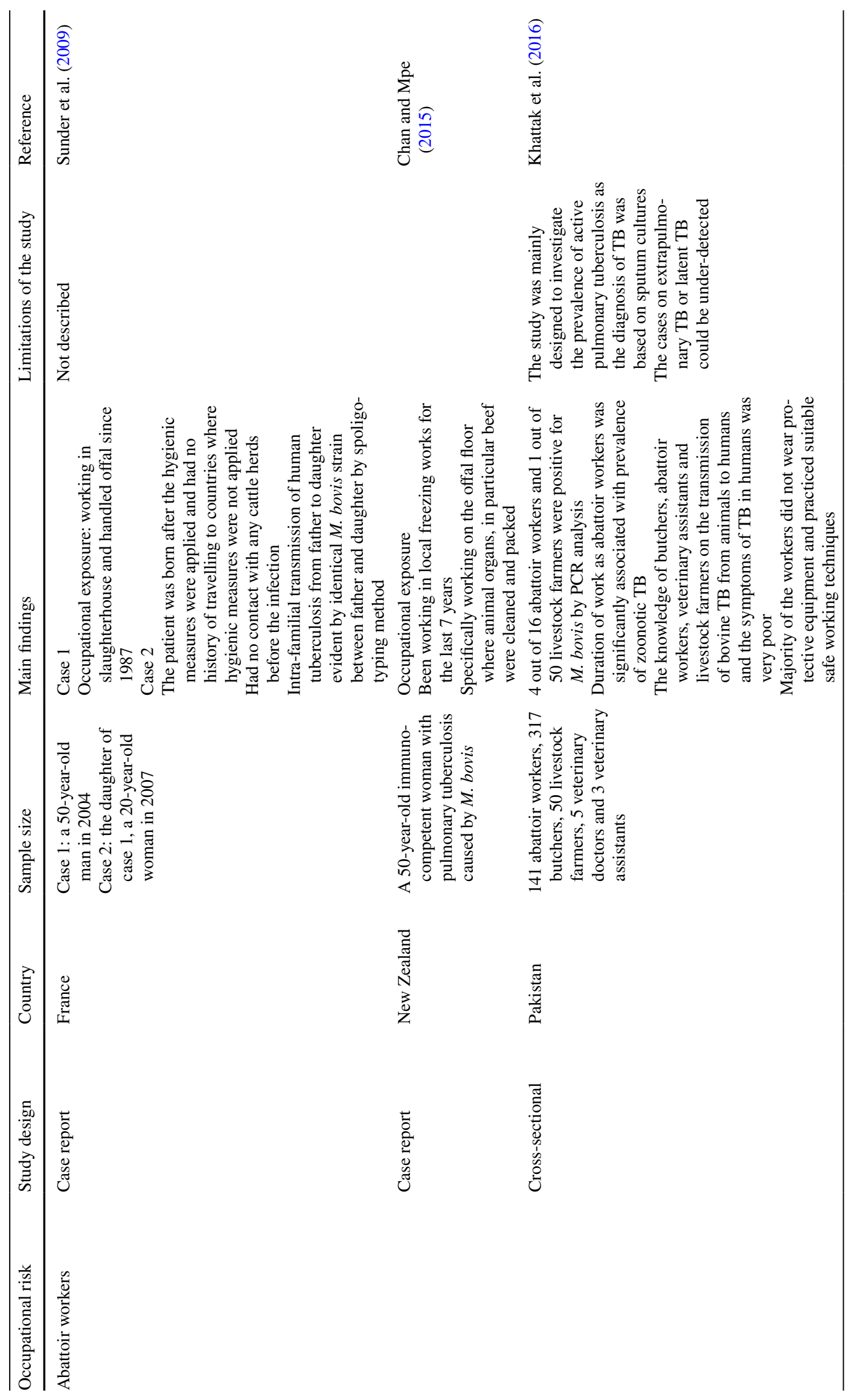




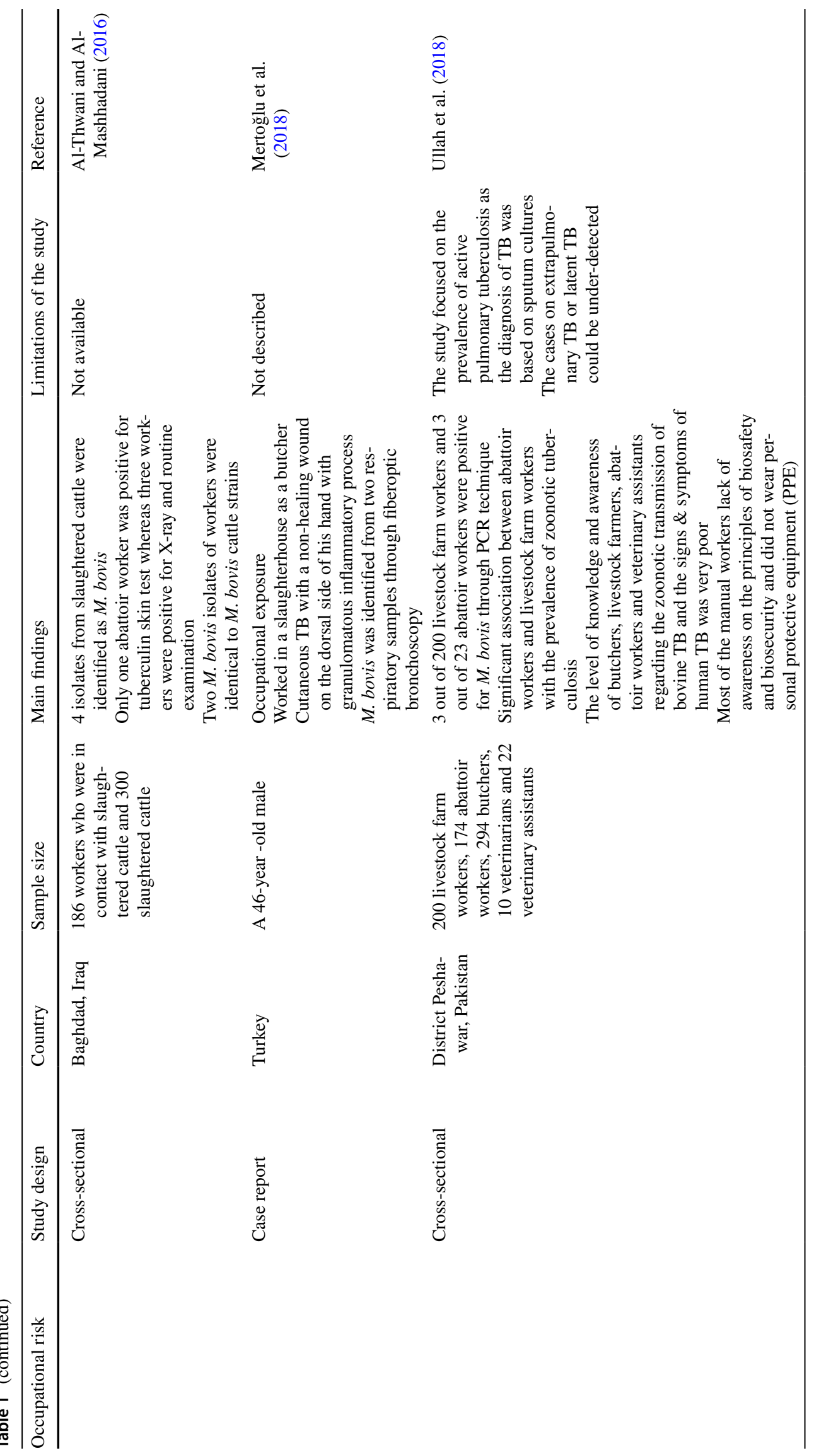




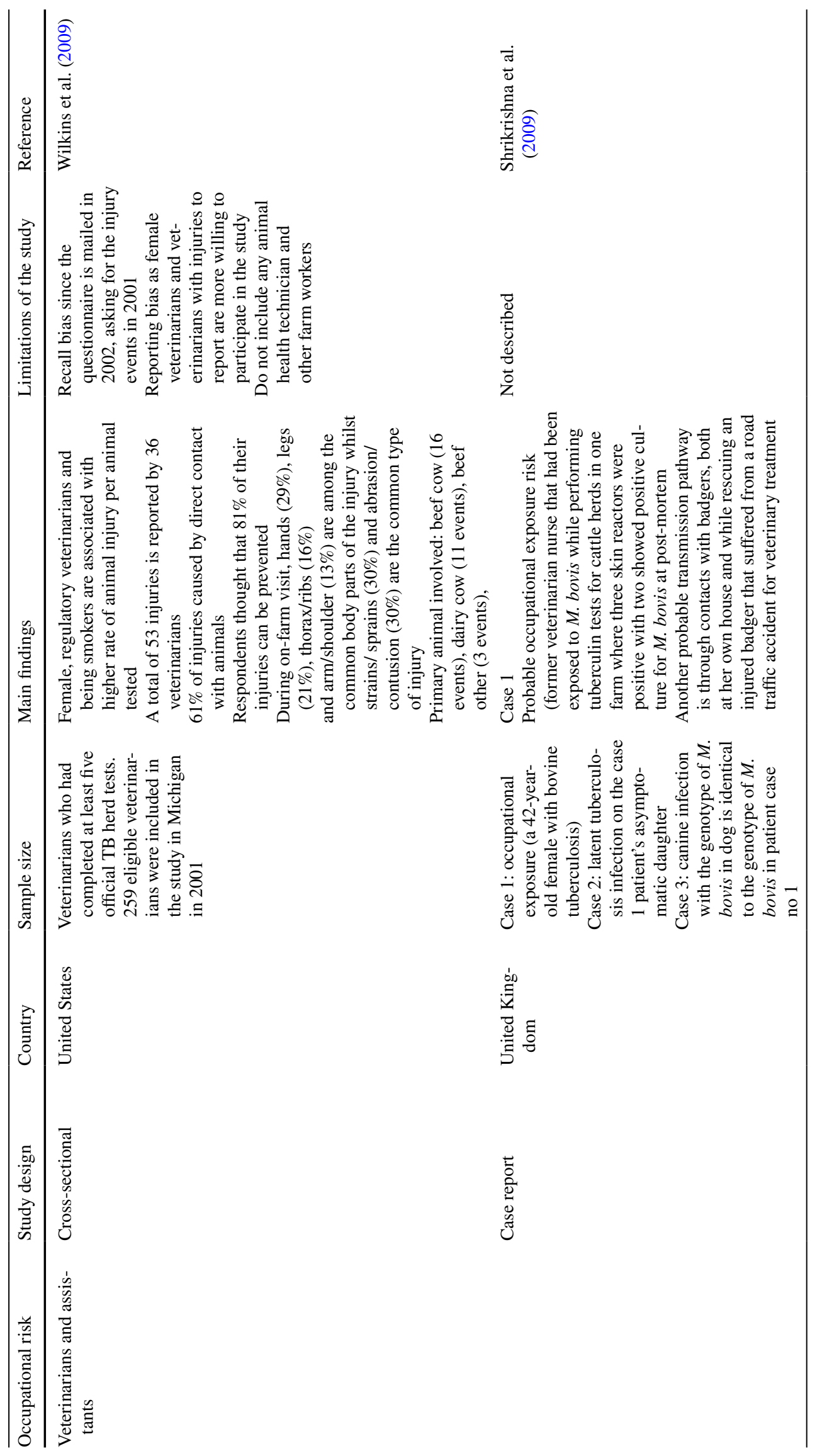




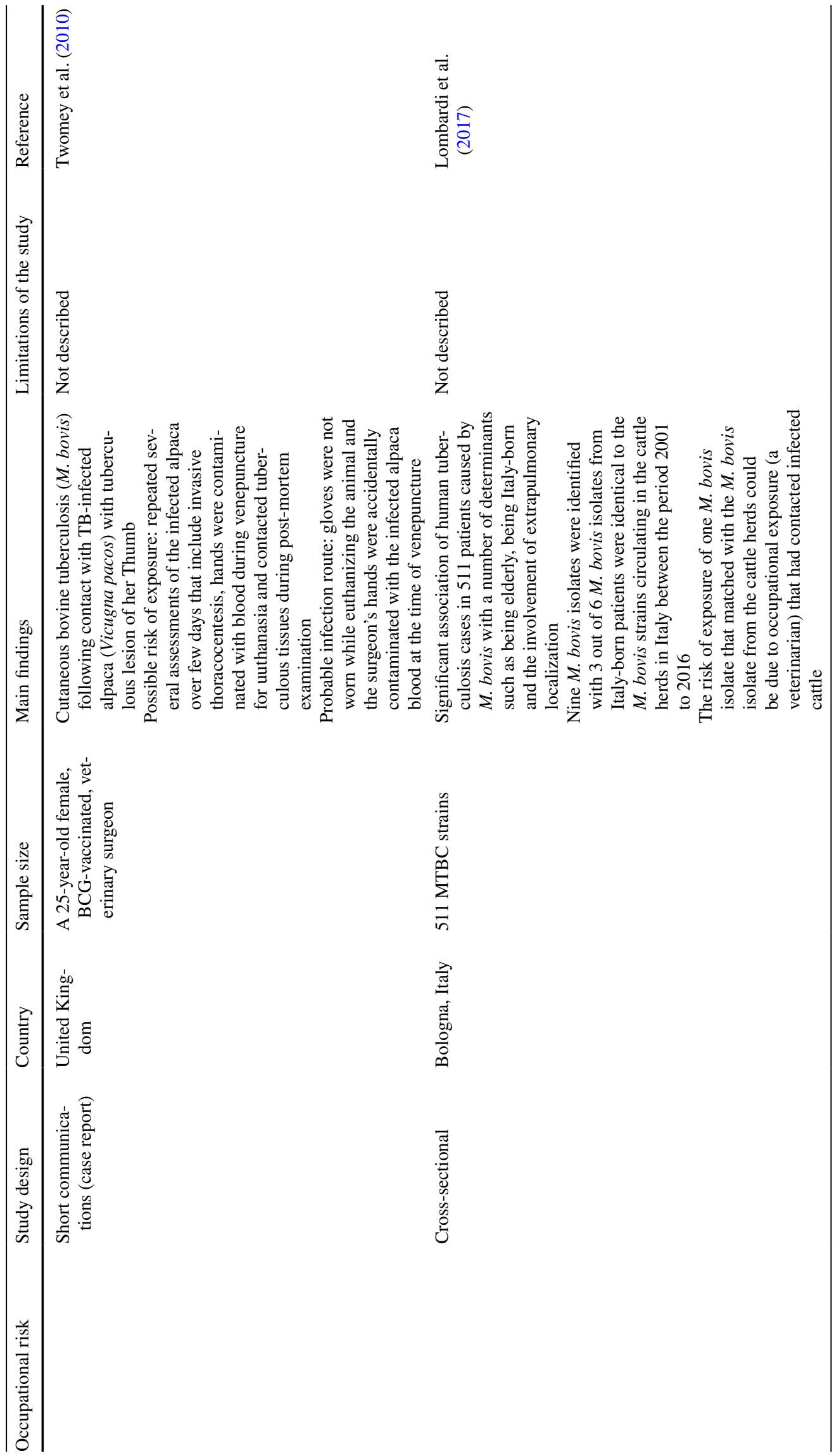




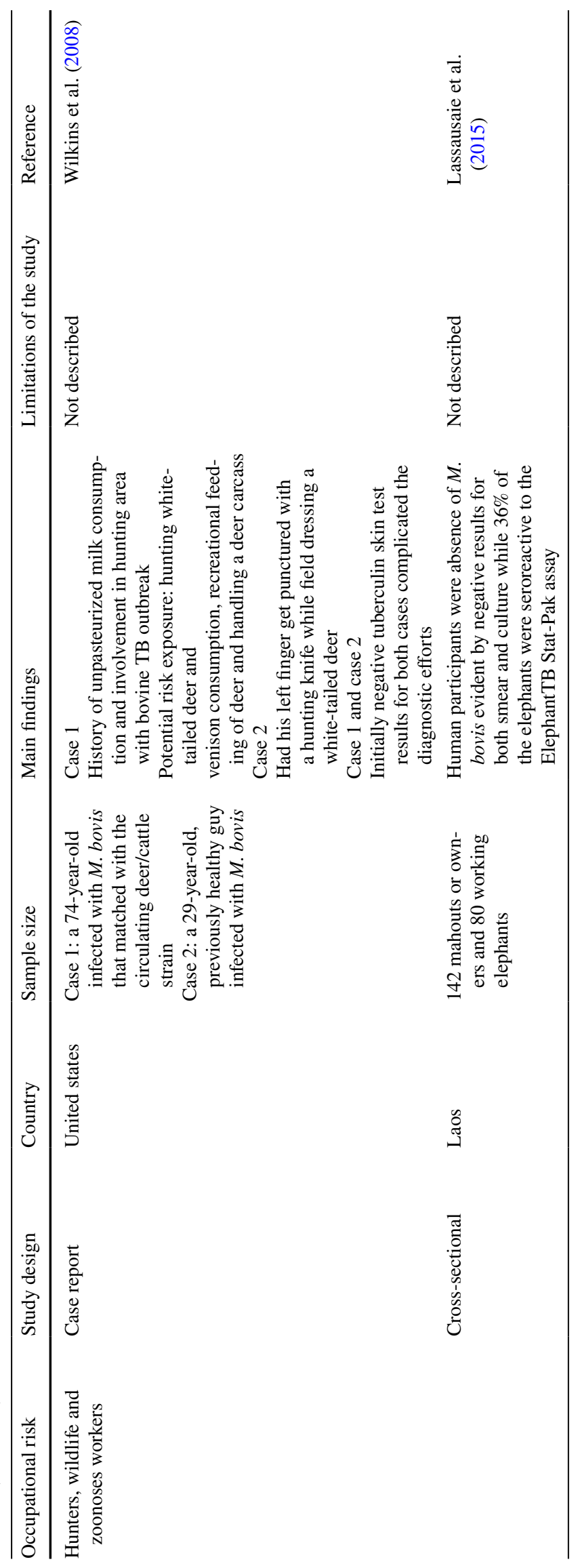


Gumi et al. 2012; Torres-Gonzalez et al. 2013). In Uganda, Oloya and his co-workers (2008) reported that $M$. bovis had been identified from three lymph node biopsies of fortythree patients with cervical lymphadenitis. Furthermore, the spoligopatterns of $M$. bovis from these human isolates are identical to the $M$. bovis isolates from infected cattle (Oloya et al. 2008). Similarly, Gumi and his teams (2012) demonstrated that identical spoligopatterns of M. bovis strains are found within the pastoralists and their livestock at SouthEast Ethiopian (Gumi et al. 2012). Torres-Gonzalez et al. (2013) also reported that one of the M. bovis strains isolated from two cases of human pulmonary tuberculosis has been found to be genetically related to bovine isolate (TorresGonzalez et al. 2013).

The transmission risk factors between livestock workers/ owners with cattle have also been implicated in different studies. Cleaveland and his collaborators (2007) had conducted a human case-control study in northern Tanzania and a cattle cross-sectional study involving 622 cattle herds and 10,549 cattle, and questionnaire surveys for 239 households. In the study, $M$. bovis is identified in seven of sixty-five $(10.8 \%)$ human cervical adenitis cases, with only one case that involved a household owning infected cattle (Cleaveland et al. 2007). A cross-sectional study conducted on 35 dairy farm owners and 384 dairy cattle in South Western Ethiopia showed that the prevalence of herds with bovine tuberculosis determined by comparative intradermal tuberculin test (CIDT) is $51.4 \%$. The study also reported that $22.9 \%$ $(8 / 35)$ of the interviewed households have at least one case of human tuberculosis in their family, and with $62.5 \%(5 / 8)$ of these families owning reactor cattle in their dairy herds (Tigre et al. 2011). Different sources also demonstrated significant association between reactor cattle and confirmed human TB cases among family members of cattle owner (Ameni and Regasa 2001; Ameni and Erkihun 2007). The presence of both reactor cattle and human TB cases in a household serve as an indicative that either human or cattle could be the main source of infection and vice versa (Cosivi et al. 1998).

A cross-sectional study revealed that $10 \%$ (7 out of 70) of livestock traders in Nigeria have positive sputum cultures from which two isolates are being differentiated as M. bovis. The risk factors associated with bovine tuberculosis in this study include prolonged cough and the duration of working years ( $>3$ years) in livestock trade. This study surmised that there could be undetected pulmonary $M$. bovis infection among livestock workers and highlighted the need to explore the risk of occupational exposure in transmitting $M$. bovis infection to larger community (Adesokan et al. 2012). Ameni et al. (2013) studied the transmission of tuberculosis between cattle and farmers in Ethiopia. The authors investigated the association between households with tuberculosis cases and households that were free from tuberculosis with herds of cattle. The authors observed that cattle owned by households with tuberculosis cases are more likely to be tested positive by CIDT than cattle owned by households that are free from tuberculosis. The authors also reported that all mycobacteria strains isolated from farmers are $M$. tuberculosis while three isolates recovered from cattle are $M$. bovis. The findings highlighted the risk of zoonotic transmission of M. bovis to humans as well as reverse zoonosis transmission of M. tuberculosis to animals (Ameni et al. 2013). A recently published study involving different areas of Eastern Ethiopia, Kemal et al. (2019) showed that 3 out of 43 farm workers $(6.97 \%)$ which had direct contact with cattle had history of tuberculosis infection. Moreover, one of the farm workers who had contracted tuberculosis infection had direct and unreserved contacts with cattle in various farms for 5 years, from which purified protein derivative (PPD) reactor cattle were identified in two of the farms that he served. This study highlighted the transmission of $M$. bovis infection from animals to humans where detailed probing on the possible sources and transmission route are needed (Kemal et al. 2019).

The risk factors that are associated to the increase in bovine tuberculosis in cattle which subsequently could heightened the transmission of $M$. bovis to humans have been identified in different studies. Cleaveland et al. (2007) reported that the prevalence of bovine tuberculosis characterized by positive CIDT test is considerably low $(0.9 \%)$ but widespread, with about $11.8 \%$ cattle herds consisting of at least one positive reactor. The prevalence of bovine tuberculosis is significantly increased with cattle age as well as other factors such as the number of cattle in the herd, herds housed within the household at night and cattle herds that have close contact with wildlife (Cleaveland et al. 2007). Another cross-sectional study involving cattle raised in a mixed croplivestock farming system in Tigray region, Ethiopia, indicated that larger herds, exotic bred, purchase of cattle and closed barn are the risk factors linked to bovine tuberculosis. The study also suggested that current dairy development programme focusing on the introduction of exotic and/or crossed animals could have influenced the epidemiological settings of bovine tuberculosis in the study area (Habitu et al. 2019). A recently published cross-sectional study involving five districts in Bangladesh suggested that older and pregnant cows within larger herds are at heightened risk of bovine tuberculosis where continuous surveillance and implementation of bovine tuberculosis control program are urgently needed (Islam et al. 2020). Collectively, most of studies discussed above show the significant association of $M$. bovis infection in livestock farmers with cattle being the possible source of infection to human although goats and other dairy animals can be infected by $M$. bovis as well (de la Rua-Domenech 2006). In-depth analysis on the risk factors for zoonotic transmission of $M$. bovis which consist of 
the assessment of the risk of $M$. bovis in cattle and other susceptible livestock, the mode of transmission from animals to human, the perception and risk practices of community should be carried out (Vayr et al. 2018; Sichewo et al. 2020).

\section{Veterinarians and assistants}

Veterinarians and assistants are also prone to $M$. bovis infections. The transmission of $M$. bovis to this occupational group could be through airborne transmission. This could likely occur when they are performing respiratory investigations or when they are conducting post-mortem analysis (Vayr et al. 2018). In addition, cutaneous transmission through skin wound or through body parts that are prone to injuries had been reported. For example, an injury survey by questionnaire had been conducted among veterinarians in Michigan in 2001. The survey analysis showed that hands (29\%) and legs (21\%) are more likely to be subjected to injury with strains/sprains (30\%) and contusion/abrasion (30\%) being the most common form of injuries sustained (Wilkins et al. 2009). One case study had documented the development of cutaneous tuberculosis caused by M. bovis in a 25-year-old female veterinary surgeon. The authors depicted that the veterinary surgeon most likely contracted the infection while euthanizing the animal without wearing gloves and at the time of venepuncture in which her hands were accidentally contaminated with infected blood (Twomey et al. 2010). Another case study illustrated the human and canine pulmonary $M$. bovis infection within the same household. The authors explained that the 42-year-old female could probably contracted $M$. bovis infection during her time as a veterinary nurse for two local practises. The female assisted in performing tuberculin tests of cattle herds where one farm that she visited was tested positive for three skin test reactors with two being culture positive for M. bovis during post-mortem examination. Also, the female could probably be infected via contact with badgers, both at her own property and while saving an injured badger that suffered from a road traffic accident for treatment (Shrikrishna et al. 2009). Lombardi et al. (2017) conducted a 5-year surveillance study on human tuberculosis caused by $M$. bovis in Italy. The authors revealed that the proportion of human tuberculosis caused by M. bovis in 511 patients is significantly associated with determinants such as being elderly, being Italian-born and extrapulmonary localization. In the study, nine $M$. bovis strains had been identified where three out of six $M$. bovis isolates of Italian-born patients resemble the $M$. bovis strains circulating in the cattle herds between 2001 and 2016. The authors reported that one of the $M$. bovis isolate that matched with the $M$. bovis isolate from the cattle herds could be explainable by occupational exposure involving direct contact between a veterinarian and infected cattle (Lombardi et al. 2017).

\section{Abattoir workers}

Abattoir workers are also at risk of exposing to and contracting $M$. bovis as they are involved in handling and manipulating infected carcasses. A cross-sectional study in Pakistan revealed that sputum specimens of one out of fifty livestock farmers and four out of sixteen abattoir workers had been identified as $M$. bovis through polymerase chain reaction (PCR). Further, the authors reported that the working hours as an abattoir worker is significantly linked with the prevalence of zoonotic TB (Khattak et al. 2016). Similarly, Ullah et al. (2018) observed that three out of twenty-three abattoir workers and three out of two hundred livestock farmers were tested positive for M. bovis via PCR in Pakistan (Ullah et al 2018). Apart from that, a study had investigated the role of infected slaughtered cattle in transmitting tuberculosis to abattoir workers in Baghdad. The authors showed that two isolates from abattoir workers are identified as M. bovis. The authors deduced that infected slaughter cattle could be the source of zoonotic tuberculosis caused by M. bovis in humans (Al-Thwani and Al-Mashhadani 2016). On the other hand, a rare case study reported a 50-year-old healthy female suffered with pulmonary tuberculosis caused by $M$. bovis. The infection is probably a consequence of occupational exposure where she had been working for almost 7 years at the local freezing works in which animal organs are clean and packed (Chan and Mpe 2015). Another rare case study documented the presence of non-healing wound on the dorsal side of the hand of a 46-year-old male who worked as a butcher in a slaughterhouse. He had been diagnosed with pulmonary tuberculosis caused by $M$. bovis coupled along with cutaneous granulomatous inflammatory reaction on his hand (Mertoğlu et al. 2018). Similarly, a case report depicted occupational exposure to $M$. bovis in a 50-year-old man who had been previously working in a slaughterhouse and involved in handling offal for quite some time. He had been diagnosed with pulmonary tuberculosis caused by M. bovis where he had most likely been occupationally exposed to $M$. bovis infection during his working periods (Sunder et al. 2009). Taken together, the findings from these studies have clearly stated that abattoir workers are exposed to the risk of contracting zoonotic tuberculosis caused by $M$. bovis as well as the possible roles of infected slaughter animals and offal in the transmission of M. bovis infection to humans.

\section{Hunters, wildlife and zoonoses workers}

Occupation-related exposure to $M$. bovis has also been documented for hunters and workers who had close contact with wildlife. Two case reports concerning hunting exposure and in contact with wildlife has been published (Wilkins et al. 2008). The first case report addresses the possible risk factors of a 74-year-old man with $M$. bovis infection. These risk 
factors include handling a buck pole where hunters showed their killed deer, handling a deer carcass, went after whitetailed deer, consumption of venison and recreational providing of food to deer. The second case report focuses on a 29-year-old deer hunter infected by a contaminated hunting knife on his left index finger while field dressing white-tailed (Wilkins et al. 2008). Together, possible occupational and recreational groups that are susceptible to $M$. bovis in deer comprise of hunters, taxidermists, trappers, venison consumers and processors (Wilkins et al. 2003). Although another study reported that $M$. bovis is not detected among 142 mahouts or owners in Laos despite high tuberculosis seroreactivity recorded in elephants, the potential of zoonotic transmission of $M$. bovis to the local wild herds and wildlife workers should not be underestimated (Lassausaie et al. 2015).

\section{Perspectives on occupational exposure and $M$. bovis infection}

Various occupational-related workers such as livestock farmers, abattoir workers, veterinarian and assistants, hunters, wildlife workers and other animal handlers who have direct or indirect contact with susceptible wildlife and domestic animals are at higher risk of contracting $M$. bovis infection. However, there are a few concerns to address in the context of occupational exposure and M. bovis infection. For instance, the significance and the reliability of the studies on occupational exposure/populations at risk and $M$. bovis infection are limited by inadequate study designs and/or insufficient sample sizes. Some of the occupational-related studies have recruited less than 200 human subjects for the analysis (Oloya et al. 2008; Gumi et al. 2012; Adesokan et al. 2012; Khattak et al. 2016; Nuru et al. 2017; Kemal et al. 2019). With zoonotic tuberculosis contributing to about 1.4\% of the global tuberculosis burden (WHO 2016), the sample sizes illustrated by majority of these available published studies are simply insufficient for robust statistical analyses. Additionally, larger scale and more inclusive studies are required to reflect the true burden of zoonotic tuberculosis caused by M. bovis in accordance to the levels of occupational risk exposure (Luciano and Roess 2020).

The available published studies concerning to occupational exposure and $M$. bovis infection are in scarcity. Most of the data are generated from developing countries and the data from, in particular industrialized and developed countries, are limited. Further, majority of the available findings on occupational exposure and $M$. bovis infection are based on subnational data confined to a limited number of countries (Oloya et al. 2008; Adesokan et al. 2012; Khattak et al. 2016; Nuru et al. 2017; Ullah et al. 2018; Vayr et al. 2018; Kemal et al. 2019; Islam et al. 2020). Hence, the narrow breadth of currently available data restricted by geographical representative and the differences in the disease prevalence across different countries, sociodemographic and economical situations as well as food consumption habits and lifestyle may not be conclusive enough to present a global picture of the occupational exposure risk, where the true exposure dynamics could be far more complicated than anticipated in other parts of the world. Otherwise, these previously established studies do provide insights on the occupational groups at risk of $M$. bovis infection, its associated transmission risk factors and transmission pathways that could be useful in the designation and the development of targeted preventive measures for better disease control and management.

The prevalence/actual burden of occupational/populations at risk of $M$. bovis infection could be underestimated by the lack of standardization in the laboratory detection techniques of $M$. bovis exemplified by various laboratory detection methods and diagnostic specimens being employed by different occupational associated studies (Oloya et al. 2008; Ameni et al. 2013; Torres-Gonzalez et al. 2013; Rahman et al. 2015; Khattak et al. 2016; Nuru et al. 2017). A systematic review by Luciano and Roess (2020) highlighted the challenges and key gaps in laboratory diagnosis of human zoonotic tuberculosis with livestock exposure in low- and middle-income countries. The authors reported that distinct studies adopted different laboratory methods including numerous different types of culture methods and/ or miscellaneous molecular detection approaches, some of which are not suitable for diagnosis of zoonotic tuberculosis in humans. This eventually could greatly affect the data reliability and the comparison of data across different occupational-related studies for a comprehensive view is therefore restricted. The authors suggested the need to have suitable and standardized laboratory diagnostic methods along with large prospective studies of at-risk populations to identify the exposure that enhanced the risk of tuberculosis conversion/infection to capture the true burden of the disease (Luciano and Roess 2020).

The risk of $M$. bovis infection is increasing globally in developing countries that have high disease prevalence. The risk factors associated with the transmission of $M$. bovis infection and the probable transmission routes involved for different occupational exposure should be carefully assessed at human-animal interface to reduce the zoonotic risk of $M$. bovis transmission to humans. The lack of veterinary health inspection to restrict $M$. bovis infection in herds coupled with a broad spectrum of breeding practices (Cleaveland et al. 2007; Tigre et al. 2011; Ameni et al. 2013; Habitu et al. 2019), working periods and health conditions of the workers (Adesokan et al. 2012; Khattak et al. 2016; Ullah et al. 2018; Kemal et al. 2019), food consumption habits such as drinking unpasteurized milk or eating raw cattle meat (Tigre et al. 2011; Cordova et al. 2012; Hambolu et al. 2013; 
Nuru et al. 2017) as well as the conditions of the cattle herds and the cattle status (Cleaveland et al. 2007; Habitu et al. 2019; Islam et al. 2020) evident by different studies could possibly explain the heightened risk of $M$. bovis transmission in occupational-related setting. The primary transmission routes in accordance to discern occupational exposure mainly involved cutaneous, respiratory transmission, which are often related to wounds and to a lesser extent food consumption practices (Vayr et al. 2018). Identification of transmission risk profiles and transmission pathways enable the designation of specific control and prevention interventions to be effectively delivered to the targeted workers at risk of $M$. bovis infection. Nevertheless, considerations that the transmission pathways and risk profiles might be varied at continental level must be taken into account. Assessment of different levels risk of occupational exposure to M. bovis infection should consider the economic, social, and geographical settings in which the studies are conducted.

Understanding the knowledge, risk perception and practises of occupational-related workers on bovine tuberculosis are crucial to reduce the transmission of M. bovis infection from animals to humans. However, the findings on the knowledge, attitude, risk perception and practises of livestock and abattoir workers towards bovine tuberculosis across different countries/regions are inconsistent with mixed findings (Tebug et al. 2014; Adesokan et al. 2018; Sa'idu et al. 2015; Kazoora et al. 2016; Khattak et al. 2016; Fekadu et al. 2018; Kemal et al. 2019). The knowledge and awareness of livestock and abattoir workers on zoonotic threat caused by M. bovis also vary depending on studies. Some studies reported good knowledge among livestock farmers and abattoir workers (Tebug et al. 2014; Adesokan et al. 2018; Sa'idu et al. 2015; Fekadu et al. 2018) while some are not (Kazoora et al 2016; Khattak et al. 2016). Sa'idu et al. (2015) reported that the awareness of bovine tuberculosis of abattoirs is significantly associated with their age, occupational status and the duration of exposure to cattle carcasses (Sa'idu et al. 2015). The increasing awareness on the disease, its transmission and zoonotic implication is important for reduction and preventive measures (Kemal et al. 2019). On the other side, some studies reported that a proportion of livestock farmers and abattoir workers are still practicing risk practises such as drinking unpasteurized milk (Tebug et al. 2014; Kazoora et al. 2016; Kemal et al. 2019) and consumption of raw cattle meat (Hambolu et al. 2013; Fekadu et al. 2018) that could expose the public to the threat of $M$. bovis infection, regardless of whether they have good knowledge or awareness of the zoonotic risk of $M$. bovis and its mode of transmission. Also, protective behaviour and practises on preventing $M$. bovis infection has been assessed. Khattak et al. (2016) revealed that majority of the abattoir workers are lacking protective equipment and do not practice safe working culture (Khattak et al. 2016).
Another study in Ethiopia revealed a lower uptake of protective behaviour in elder (Age $>30$ years old) and male demographics. Improvement of zoonotic prevention programme as well as further interrogation into the prevalence and risk determinants for zoonotic tuberculosis caused by M. bovis are highly recommended (Tebug et al. 2014). Also, public health interventions should not just be tailored towards increasing the awareness of zoonotic risk but should also be focusing on promoting the behavioural change such as the habit of eating raw meats to effectively prevent and control zoonotic tuberculosis (Fekadu et al. 2018).

Heath education has been implicated as one of the effective approaches in dealing with zoonotic tuberculosis. A study by Kazoora et al. (2016) surmised the need of health education in improving the attitudes of herdsman and other farm workers towards zoonotic tuberculosis. It has been demonstrated that health education on zoonotic tuberculosis imposes positive impact on the knowledge, attitudes, and behaviors of the respondents where good knowledge is significantly associated with practices that prevent disease transmission (Kazoora et al. 2016). Indeed, understanding that bovine tuberculosis as a zoonotic disease by cow owners are deem critical for policymakers to strategize appropriate control plans that could alleviate the public health threats it poses (Munyeme et al. 2010). The acceptability and the success of the control measures encompassing routine tuberculosis surveillance, compulsory milk pasteurization and meat inspection, restriction in cattle movement are highly reliant on the knowledge of cattle owners and their perceived risk of contracting the disease. Nevertheless, raising the awareness of zoonotic tuberculosis through health education in highrisk communities has been considered as the only feasible preventive approach in developing countries where testing and cattle slaughtering as well as mandatory pasteurization of milk and its products are not routinely being practiced (Wedlock et al. 2002; McGeary 2008; Kazoora et al. 2016).

Further studies should emphasize on evaluating occupational exposure to $M$. bovis infection of distinct high-risk populations and/or occupational groups in industrialized countries. A systematic review analysis on the occupational exposure to M. bovis infection conducted by Vayr and his collaborators (2018) highlighted that the primary prevention modalities in high-risk occupational groups have yet to be defined despite the diagnosis and treatment for bovine tuberculosis being well established. Preventive measures can be designed in a way that focus on the probable M. bovis transmission pathways for different occupational-related workers. For example, livestock workers are susceptible to respiratory transmission of $M$. bovis because of their direct and unreserved contact with cattle, and thus respiratory protective masks should be applied while handling infected cattle with respiratory symptoms. Cutaneous transmission of $M$. bovis through a cut or wound could possibly occur 
in occupational-related workers such as abattoir workers, veterinarians and their assistants and workers in close contact with wildlife animals, and, therefore, protective gloves should be used while working with infected animals. Furthermore, occupational-related workers should be given exposure on the clinical signs of $M$. bovis infection, its mode of transmission and associated transmission risk factors and ways to handle sick animals to abate the risk of transmission (Vayr et al. 2018). A specific guideline which is tailored to the degree of occupational exposure as well as taking good care of occupational-related workers exposed to $M$. bovis infection is highly warranted. Indeed, in France, the guideline and recommendations on monitoring occupationalrelated workers after being exposed to bovine tuberculosis has been published recently. This guideline will eventually lead to better management of workers after being exposed to $M$. bovis in an occupational setting (Deffontaines et al. 2013).

\section{Tackling $M$. bovis infection at human-animal interface}

\section{Overview}

Outbreaks of severe acute respiratory syndrome coronavirus 2 (SARS-CoV-2) (Huang et al. 2020), Zika virus (Sikka et al. 2016) and Middle East respiratory syndrome coronavirus (Annan et al. 2015) have raised the awareness of public health in disease management and surveillance and also highlighted the important of One Health approach in tackling zoonotic infections. Zoonotic tuberculosis has long been recognised. However, the burden of this disease cannot be fully elucidated without a comprehensive understanding of the multispecies host-pathogen ecosystem (Carruth et al. 2016). Furthermore, the epidemiology of zoonotic tuberculosis varies among different geographical regions and is influenced by a number of determinants, for instance, human, socio-economic status of countries, livestock and wildlife populations, environmental conditions and existing tuberculosis control programme (Marie-France et al. 2009) which further complicates the control of zoonotic tuberculosis. To prompt a better control over zoonotic tuberculosis, a closer look into animal reservoir and the risk of transmission at animal-human interface is required (Teppawar et al. 2018). Thus, this section discusses on various approaches being employed in tackling $M$. bovis infection at animal-human interface.

\section{Human component and $M$. bovis infection}

A few studies highlighted the society values and human perceptions as well as the role of humans in the control and management of bovine tuberculosis and zoonotic risk of M. bovis in humans. From the perspective of public health, universal pasteurization of milk and eradication programs in cattle remain the most prominent approaches to prevent interspecies transmission of M. bovis (Sa'idu et al. 2015). A retrospective study by Borja et al. (2018) revealed that although bovine tuberculosis control program has been implemented in Fiji since 1980, disease reduction and containment of the infection are not being achieved. The authors identified various factors attributed to this scenario which include the relevance of single intradermal test (SID) protocol in cattle, inadequate training for staffs to conduct tuberculosis testing, lack of movement control of cattle, absence of standard protocols for data collection and evaluation as well as the presence of stray cattle. Revision on the control program by relevant authorities had increased the detection rates following an apparent bovine tuberculosis outbreak in some farms, but also raised concerns for the local livestock industry, in particular serious economic impact on individual farmers due to loss of cattle. Overall, the study highlighted the challenges involved in bovine tuberculosis control and the need for consideration of technical and social aspects for effective disease control (Borja et al. 2018). In another study, Meiring et al. (2018) used the implemented strategies employed for human TB control in South Africa as an example to explain and compare the feasibility of applying these strategies in bovine tuberculosis control. The authors explained that the mitigation of human TB incidence in this high burden country has been accomplished by increasing awareness of tuberculosis in public and antimicrobial therapy where both elements are lacking for bovine tuberculosis. The authors addressed a number of determinants such as lack of movement restrictions and proper monitoring of animals, inadequacy of veterinary resources and mandatory testing program or bovine tuberculosis, point-of-care diagnostic testing for cattle and the prevalence of bovine tuberculosis in wildlife may be responsible for the persistence of disease. The authors suggested that multisector collaborations are much needed to control bovine tuberculosis (Meiring et al. 2018).

A semi-structured interview evaluating the attitude among farmers and veterinarian in Northern Ireland on the risk of contracting $M$. bovis infection depicted that the risk of $M$. bovis infection is often downplayed and is no longer being considered as a public health risk due to intensive surveillance on farms and pasteurisation of milk evident by the low-recorded human incidence. Nevertheless, the authors highlighted the needs to revise the attitude and practice by the stakeholders on the occupational and public health threats of $M$. bovis infection including developed nations with ongoing bovine tuberculosis eradication programmes (Robinson 2019). A study assessing the health system, policy and dairy farm-level factors which could have 
impact on the zoonotic transmission have been performed in smallholder peri-urban dairy farms in India (Chauhan et al. 2019). The study focuses on three main themes encompassing knowledge and practices related to bovine tuberculosis, limited system support for prevention and control of bovine tuberculosis and lack of effective policies and programmatic direction in the context of bovine tuberculosis. The authors highlighted the risky practices of dairy farmers in diseases transmission and also risky behaviour as a result of inadequate knowledge and awareness in the presence of extension services. Furthermore, the authors also reported that the absence of effective policies and the perception of stakeholders on bovine tuberculosis remain as significant barriers in controlling bovine tuberculosis. The authors suggest that these gaps can be addressed through collaborative research and One Health approaches (Chauhan et al. 2019).

Rahman et al. (2015) pointed out that poor farm biosecurity and poor nutrition are significant management-associated risk factors of bovine tuberculosis in cattle at farmers' level (Rahman et al. 2015). A recently published study also showed the significant association of the positivity of tuberculin test with herd management. Farms that have been managed poorly are at 3.6 times greater risk for bovine tuberculosis than farms with good management (Kemal et al. 2019). Similarly, different sources also reported higher bovine tuberculosis incidence in farms under poor management status (Radostits et al. 2006; Tsegaye et al. 2010; Gumi et al. 2011). Good sanitary measures which improve the hygiene conditions of farms could then prevent the occurrence of bovine tuberculosis (Kemal et al. 2019). Taken together, involvement of human component in the control of bovine tuberculosis and human perceptions such as knowledge, risk behaviour and practical risk, society values, and perceived cost-benefits of interventions have great influential power in disease propagation and disease control and management (Byrne et al. 2019). The findings from these studies could serve as baseline data or as recommendations for policy- and decision-makers to take proper interventions or decisions in alleviating the impact of bovine tuberculosis on public health, occupational and veterinary settings.

\section{Modelling approach and $M$. bovis infection}

The application of different types of disease-modelling approaches of varying complexity in the context of animal health have been well-implicated in policy development, design and assessment of surveillance programs and as predictors of the consequences arising from the introduction of new diseases and the impact of diseases on control measurements (Garner and Hamilton 2011; Willeberg et al. $2011 \mathrm{a}, \mathrm{b})$. In bovine tuberculosis, various disease models have been applied to provide estimates on the transmission rates within- and between-herds (Brooks-Pollock et al. 2014;
Alvarez et al. 2012; Perez et al. 2002), the latency period of the disease (Smith et al. 2013a, b; Conlan et al. 2012; Fischer et al. 2005), the efficacy of the bovine tuberculosis diagnostic tests (Smith et al. 2013a, b; Conlan et al. 2012; Fischer et al. 2005), the disease dynamics in wildlife populations and their contributions to the disease incidence and/ or persistence in livestock (Anderson et al. 2013; Delahay et al. 2013; Graham et al. 2013) as well as the efficacy of alternative control approaches in wildlife reservoirs and cattle (Hardstaff et al. 2013; Smith et al. 2013b; Fischer et al. 2005). These distinctive disease models including statistical, mathematical and simulation modelling enable the elucidation of relationship between different parameters, allowing the comprehensive analysis of disease transmission dynamics and mechanistic aspects of the disease transmission as well as providing useful windows on the proper control and management of $M$. bovis infection at animal-human-wildlife interface. For instance, Brooks-Pollock et al. (2014) presented a dynamic stochastic spatial model which incorporated within-farm and between-farm transmission for bovine tuberculosis in Great Britain. The proposed model replicates the observed yearly increase of infection over time, the spreading of infection into new regions as well as identification of the transmission routes attributed to most of the newly detected cases which include movement of infected cattle, poor sensitivity of diagnostic test and reinfection caused by environmental reservoir, which could have huge implications on control measures on bovine tuberculosis (Brooks-Pollock et al. 2014).

A mathematical model which explains the transmission dynamics of bovine tuberculosis in both cattle and buffalo populations is established. The study highlighted the importance to include both cross- infection and contaminated environmental transmission routes in the transmission of bovine tuberculosis. Also, simulation analysis documented that bovine tuberculosis has more detrimental effect on cattle populations compared to buffalo populations when all transmission paths are taken into consideration. Nonetheless, factors such as seasonality, treatment, vertical transmission route, age classes of both buffalo and cattle populations and the role of temperature in determining the survival of $M$. bovis in the environment should be taken into account (Phepa et al. 2016). In another study, Brunton and his colleagues (2018) employed statistical survival models to study the future risk of cattle herds that contain inconclusive reactor animals to the tuberculin skin test. The authors demonstrated that significant higher future risk in herds with inconclusive reactors detected in comparison to those negative herds, which warrants a careful decision-making when dealing with the management of inconclusive reactors to reduce the risk of bovine tuberculosis (Brunton et al. 2018). Raphaka et al. (2018) had developed a stochastic geneticepidemiological model which introduces genetic selection 
in a simulated cattle population to evaluate the impact of genetic influence for increased bovine tuberculosis resistance on disease prevalence and dynamics in UK. The genetic model revealed that genetic selection over generations could substantially reduce the prevalence and severity of bovine tuberculosis, suggesting that genetic selection could be another approach that can be utilised to complement the existing surveillance and management strategies to control and subsequently eradicate bovine tuberculosis (Raphaka et al. 2018). Similarly, a study by Tsairidou et al. (2018) via genetic-epidemiological prediction models and simulation studies suggested the integration of infectivity into cattle breeding schemes which could increase and accelerate the reduction in breakdown risk of bovine tuberculosis than selection on resistance alone (Tsairidou et al. 2018).

Simulation and mathematical modelling have become an essential tool for bovine tuberculosis control, especially where wildlife reservoirs are involved. Different models have been developed to explore bovine tuberculosis infection and wildlife reservoirs. A stochastic model is developed to assess the factors that drive the spreading of bovine tuberculosis in possum population. It is found that social contact promotes the dissemination of the infection (Barlow 1991). A spatial stochastic model is used to examine fertility control as a potential approach to control bovine tuberculosis in badgers. The study reported that fertility control alone is unable to completely eradicate bovine tuberculosis from badger populations in UK. However, it could be effective if culling is used as part of the integrative strategy (White et al. 1997). A non-linear transmission comprising of susceptible and infected possum populations is developed. The model has been applied to explain the dynamics of bovine tuberculosis in a heterogenous possum population that taken into consideration the patchy distribution of the infection (Barlow 2000). A recently published review by Smith and Delahay (2018) provided a summary on different badger bovine tuberculosis models and their roles in supporting decision-making on controlling bovine tuberculosis in wildlife. The authors surmised that integration of cattle into badger tuberculosis models enabled the comparison of the predicted impacts of various badger management approaches on the breakdown rates of cattle herds as well as provided an economic perspective to the control outputs. Also, based on a cohort of recent models, the authors documented that combinatorial strategies which involve management of both host species (cattle and badger) coupled with vaccination might be the most effective method to control bovine tuberculosis. The authors also provided descriptions on how these models could better reflect the epidemiological and ecological complexities of the cattle-badger tuberculosis model and the utilisation of modelling for the management interventions of bovine tuberculosis. The authors also highlighted how future data collection can be incorporated into modelling endeavours and is being optimally utilised by such model (Smith and Delahay 2018).

\section{Wildlife reservoir and $M$. bovis}

Wildlife animals are considered as maintenance hosts for $M$. bovis which include the white-tailed deer in Michigan, USA, European badger in United Kingdom and Ireland, Australian brushtail possum in New Zealand (Bengis et al. 2002) and Eurasian wild boar in the Iberian Penisula, Spain (Naranjo et al. 2008). Furthermore, African buffalo in South Africa (de Klerk et al. 2010), red deer in different parts of Europe (Santos et al. 2015), wapiti and wood bison in Canada (Nishi et al. 2006) also remain as maintenance hosts responsible for infection in national parks and hunting estates. These plethora of maintenance hosts can be the sources of $M$. bovis infection for domestic animals and/or in natural parks and the infection can spill over to infect other unique wildlife species such as lions, wild dogs, leopard and Iberian lynx (Buddle et al. 2018). Effective control and eradication of bovine tuberculosis in domestic animals cannot be accomplished without prompt disease control in wildlife reservoir populations. Partial disease control is attainable in these maintenance hosts thorough reducing/minimising contact with livestock, lowering the density of animals or stopping artificial feeding that could heightened the local densities of animals (Griffin et al. 2005; O'Brien et al. 2006; Livingstone et al. 2015). The development and use of vaccine to control M. bovis infection in wildlife populations are deemed important to limit the spreading of infection to domestic livestock. A review by Buddle et al. (2018) proposed that the adoption of oral Bacillus Calmette Guerin (BCG) vaccination could be one of the approaches that can effectively control and confer protection in wild animals such as European badgers, wild boar, brushtail possums, and deer against bovine tuberculosis (Buddle et al. 2018). Likewise, another review by Palmer and Thacker (2018) also documented that the alleviation of disease severity in deer vaccinated with human BCG are likely accompanied by reduction in disease transmission which in turn can diminish the spreading of M. bovis infection to livestock from wild animals (Palmer and Thacker 2018). Nevertheless, to optimally utilise BCG vaccine, it will be imperative for the continuity of field test BCG vaccine in numerous animal species under different environments, husbandry systems, varying levels of disease prevalence and the evaluation of the practicality of differentiate infected from vaccinated animals (DIVA) tests (Buddle et al. 2018). Besides vaccination, species-specific diagnostic kits for wildlife are recommended to ease monitoring and to circumvent the disease from circulating outside of monitored hosts (Meiring et al. 2018).

Understanding the possible transmission routes of $M$. bovis infection between wildlife and domestic animals are 
crucial for disease management. Bouchez-Zacria and his co-workers (2018) adopted a network modelling approach to assess the involvement of different types of contact in the transmission of M. bovis between cattle farms of southwest France. The authors analysed the empirical network that consists of cattle farms with known infection status and molecular types as nodes along with cattle trade data as well as badger contact networks that built from inferred badger home ranges as edges. The study demonstrated how both cattle trade and spatial relationships between cattle farms together with linkages that related with badger territorial behaviour could lead to increased risk of contracting $M$. bovis infection, highlighting multifactorial $M$. bovis transmission and also the complexity of multi-host epidemics (Bouchez-Zacria et al. 2018). In another study, Cosgrove et al. (2018) used a spatially explicit stochastic simulation model to interrogate the effects of attractiveness of feeding sites, feed density and spatial and temporal persistence on the prevalence of bovine tuberculosis in wild deer and subsequent interspecies transmission in cattle. The study demonstrated that extended recreational feeding or winter supplemental feeding is likely enhance bovine tuberculosis transmission by extending temporal availability. The authors showed that feeding deer is not just an issue limited to wildlife managers and hunters, but also for agriculture agencies and cattle producers as well (Cosgrove et al. 2018).

Brook et al. (2013) suggested that the management actions to avoid transmission risk of tuberculosis at the wildlife-livestock interface can be achieved through a "bottom up" approach that concentrates on practical, farm-based mitigation approaches. Such strategy can be applied on individual farm operators, is considerably low cost and is widely supported by farmers compared to other extreme and controversial alternatives such as wildlife eradication (Brook et al. 2013). It has undoubtedly changing farm management could substantially reduce the transmission risk between livestock and wildlife animals (Brook et al. 2013; Lavelle et al. 2016; Ribeiro-Lima et al. 2017). The importance of proper on-farm biosecurity in management of bovine tuberculosis has been addressed. VerCauteren and his co-workers (2018) provide a summary of the history and progress of research on farm biosecurity undertaken in Michiganto date and the lessons acquired in managing bovine tuberculosis The authors also suggested to increase management actions to combat $M$. bovis infection in deer that includes vaccination of wild deer, strategic management habitat manipulations to redistribute deer from farms and precision culling of deer in proximity to high-risk farms, which could aid in preventing the transmission of $M$. bovis from deer to cattle (VerCauteren et al. 2018). Also, the increased on-farm biosecurity could probably reduce the cattle herd breakdowns caused by wild deer (Ramsey et al. 2016). Such approach could serve as a valuable experience sharing which can be applied in managing and preventing $M$. bovis infection in other wild animals and subsequent interspecies transmission of the infection to domestic animals.

When human health is being threatened during the transmission of zoonotic diseases, the options for intervention usually require insights from stakeholders whose discerning values systems attributed to decision on disease management Gormley and Corner (2018) assessed the role of different stakeholder values systems in wildlife interventions and tuberculosis control and eradication strategies in several countries. The authors identified that the determinants influencing the consensus on disease management and control strategies rely on the infected species in concerned (reservoir status and the society value inferred to each species), ethical considerations on culling sentient wild animals, types of interventions being proposed and the concerns on economic cost-benefit effectiveness. The review also reported that interventions that are generally being accepted in one region may not be acceptable in another area, even amongst widely similar stakeholder groups. Effective control of tuberculosis warrants identification and long-term engagement with all crucial stakeholders to reach consensus on ethical frameworks that emphasize and justify control options, especially where sacrificing wild animals is concerned (Gormley and Corner 2018). Using white-tailed deer in USA as a study model, Cross et al. (2018) adopted the risk information seeking and processing (RISP) model to assess how deer hunters seek out information on probable human health risks relating to $M$. bovis exposure from which could assist managers to collect data necessary to decision-making on future management outcomes. It also enables us to better know how stakeholders acquire knowledge and their perceptions on disease management in wildlife. Such RISP model approach could potentially be applied across a wide spectrum of studies related to veterinary disease management in future (Cross et al. 2018).

Potential zoonotic risks to humans from hunting and wildlife consumption also offer different perspectives. Many potential zoonotic pathogens are transmitted from wildlife to humans through wild meat trade (Cantlay et al 2017). Since the availability of wild meat varies between species, the chances of contracting zoonotic in humans from the pathogens are more likely to occur through wildlife trading as well (Cantlay et al 2017). Also, owing to the wildlife trade distribution networks which allow regional movement of animals and cross-species transmission of pathogens from numerous species of different sources and within the close proximity between wildlife and humans could be another concern (Karesh et al. 2007). Therefore, detailed probing on wildlife trading is needed to prevent the risk of zoonotic transmission and cross-species infection. A nationwide surveillance system across different geographical regions for $M$. bovis testing and transmission data should be established to 
capture the real scenario of bovine tuberculosis in domestic and wildlife reservoir populations.

\section{Diagnosis challenges of $M$. bovis at animal-human interface}

In developing countries, the global burden of bovine tuberculosis (BTB) among human population is around $10 \%$, which attributes to $2.1 \%$ of pulmonary $\mathrm{TB}$ and $9.4 \%$ of extrapulmonary TB cases (Hambolu et al. 2013). Current diagnosis for human TB focuses on pulmonary diseases caused by M. tuberculosis while zoonotic TB caused by $M$. bovis often results in extrapulmonary diseases which eventually result in a slight delay in treatment (Cousins et al. 1989; Carruth et al. 2016; Teppawar et al. 2018). Added to this, M. bovis is clinically undistinguishable from M. tuberculosis along with inconclusive findings using tuberculin skin test and direct smear microscopy further complicated the diagnosis and prompt treatment of patients infected with M. bovis (Centers for Disease Control and Prevention 2016; WHO 2016; Olea-Popelka et al. 2017). Moreover, in most developing countries, direct smear microscopy is the only method to diagnose tuberculosis, where species speciation is impossible under this circumstance. This will further limit the collection of diagnostic data for surveillance study and also impair the efficacy of the treatment. On the other hand, $M$. bovis is intrinsically resistant towards pyrazinamide, a standard first-line anti-TB drug. Without prompt diagnosis and drug susceptibility testing, patients with zoonotic TB may receive less effective treatment. Moreover, some $M$. bovis strains exhibit resistance to other first-line anti-TB drugs such as isoniazid and rifamcipin. The resistance to at least two first-line anti-TB drugs will result in multidrug resistance phenomenon, which is an emerging public health threat globally and poses huge challenges on human tuberculosis control and treatment (Carruth et al. 2016; Teppawar et al. 2018). Altogether, rapid and affordable molecular diagnostics tools with high sensitivity and specificity are warranted for the diagnosis of $M$. bovis infection. In view on this, the application of omics and high throughput sequencing technologies may offer undisputable role in the breakthrough of diagnosis and treatment of $M$. bovis-related infection.

In developed countries, bovine tuberculosis control program in animals, particularly in cattle has been probed by test and slaughter procedures, which consist of comparative intradermal tuberculin skin test (CIDT) or intradermal tuberculin test to identify infected animals, followed by isolating and immediate slaughter and necropsy to examine tuberculosis-associated lesions. (Cousins 2001; Wedlock et al. 2002). A large numbers of low-middle income countries do implement this kind of policy; however, it is usually neither being well-executed, nor sufficiently funded to support the program (Wedlock et al. 2002). Apparently, suspicion or surveillance of bovine tuberculosis should not be proceeded with immediate slaughter and necropsy. A more attainable way is to test and separate tuberculosis-positive animals from uninfected animals without immediate killing. Only under robust diagnostic evidence should post-mortem analysis, culture and species speciation be conducted to confirm bovine tuberculosis. Invention of non-lethal or non-invasive diagnostic tools or biomarkers is strongly suggested to overcome this issue. For example, Lorente-Leal et al. (2019) had developed a real-time PCR assay based on the $m p b 70$ gene to detect the presence of mycobacteria species in clinical bovine tissue specimens. The assay developed displayed good sensitivity and specificity when compared to bacteriological culture and could be potentially employed to detect Mycobacterium tuberculosis complex in animal tissues (Lorente-Leal et al. 2019). A study by Hadi et al. (2018) had discovered immune complex proteins from $M$. bovis in experimentally infected cattle through multidimensional proteomic approach which could be potentially applied to diagnose bovine tuberculosis. The authors also suggested ways to improve the method before validation on larger datasets is performed (Hadi et al. 2018). Effective bovine tuberculosis control urges the need to continuously invest and develop diagnostic tools and control programs that fit all susceptible M. bovis hosts. Prompt diagnosis and treatment are required to avoid unnecessary downstream cost, or to prevent any ongoing disease transmission and propagation. Therefore, considerable efforts with sustainable investments in the best diagnostics and interventions programs to implement these measures are well justified.

\section{Conclusion}

Accumulated evidences revealed the threat of $M$. bovis infection on public and veterinary health systems. The lack of public awareness on zoonotic tuberculosis and its consequences is definitely a serious concern and something to ponder on. Nationwide and global surveillance and reporting systems across different countries on bovine tuberculosis are warranted to reflect the true burden of the disease. Ongoing research into better diagnosis tools helps to accurately identify the mycobacteria species for prompt treatment or management in both animals and humans. The growing risks of occupational exposure to bovine tuberculosis necessitate the collaborations from multi-sectoral to prevent disease transmission and propagation at animal-human interface. Larger scale studies involving different geographical regions are recommended to assess the impact of $M$. bovis infection and the risk of occupational exposure. Identification of specific occupational-related workers/populations at risk along with proper implementation of preventive 
measures and specific guidelines could aid in disease management and control of M. bovis infection.

Acknowledgements This review is supported by Geran Galakan Penyelidik Muda (GGPM2017-118) under Universiti Kebangsaan Malaysia. The authors also wish to thank Department of Community Health, Faculty of Medicine, Universiti Kebangsaan Malaysia for providing kind assistance in the literature search for this review.

Author contributions $\mathrm{VKC}$, SAN and RI conceptualized the idea of this review paper. RDK, VKC, LJL and TYL performed the literature search for the review. RDK, VKC and TYL drafted the review. RI, SAN and $\mathrm{VKC}$ revised the review. All the authors agreed to the final draft of this review paper.

Funding This review is supported by Geran Galakan Penyelidik Muda (GGPM2017-118) under Universiti Kebangsaan Malaysia.

\section{Declarations}

Conflict of interests The authors declare that they have no conflict of interest.

\section{References}

Adesokan HK, Jenkins AO, Van Soolingen D, Cadmus SI (2012) Mycobacterium bovis infection in livestock workers in Ibadan, Nigeria: evidence of occupational exposure. Int J Tuberc Lung Dis 16:1388-1392

Adesokan HK, Akinseye VO, Sulaimon MA (2018) Knowledge and practices about zoonotic tuberculosis prevention and associated determinants amongst livestock workers in Nigeria; 2015. PLoS ONE 13(6):e0198810

Al-Thwani AN, Al-Mashhadani MS (2016) Tuberculosis in slaughtered cattle and workers in some abattoirs of Baghdad governorate. Int J Mycobacteriol 5:S250-S251

Alvarez J, Perez AM, Bezos J, Casal C, Romero B, Rodriguez-Campos S, Saez-Llorente JL, Diaz R, Carpintero J, de Juan L, Domínguez L (2012) Eradication of bovine tuberculosis at a herd-level in Madrid, Spain: study of within-herd transmission dynamics over a 12 year period. BMC Vet Res 8:1-8

Ameni G, Erkihun A (2007) Bovine tuberculosis on small-scale dairy farms in Adama town, central Ethiopia, and farmer awareness of the disease. Rev Sci Tech 26:711-720

Ameni G, Regasa A (2001) Survey on bovine tuberculosis in cattle and its public health implications to cattle raising families in Wolaita Soddo, Southern Ethiopia. Ethiop J Anim Prod. 1:55-62

Ameni G, Tadesse K, Hailu E, Deresse Y, Medhin G, Aseffa A, Hewinson G, Vordermeier M, Berg S (2013) Transmission of Mycobacterium tuberculosis between farmers and cattle in central Ethiopia. PLoS ONE 8(10):e76891

Anderson DP, Ramsey DS, Nugent G, Bosson M, Livingstone P, Martin PA, Sergeant E, Gormley AM, Warburton B (2013) A novel approach to assess the probability of disease eradication from a wild-animal reservoir host. Epidemiol Infect 141:1509-1521

Annan A, Owusu M, Marfo KS, Larbi R, Sarpong FN, Adu-Sarkodie Y, Amankwa J, Fiafemetsi S, Drosten C, Owusu-Dabo E, Eckerle I (2015) High prevalence of common respiratory viruses and no evidence of Middle East respiratory syndrome coronavirus in Hajj pilgrims returning to Ghana, 2013. Trop Med Int Health $20: 807-812$
Baker MG, Lopez LD, Cannon MC, De Lisle GW, Collins DM (2006) Continuing Mycobacterium bovis transmission from animals to humans in New Zealand. Epidemiol Infect 134:1068-1073

Barlow ND (1991) A spatially aggregated disease/host model for bovine $\mathrm{Tb}$ in New Zealand possum populations. J Appl Ecol 28:777-793

Barlow ND (2000) Non-linear transmission and simple models for bovine tuberculosis. J Anim Ecol 69:703-713

Bengis RG, Schmitt SM, O'brien DJ (2002) Tuberculosis in freeranging wildlife: detection, diagnosis and management. Rev Sci Tech 21:317-334

Borja E, Borja LF, Prasad R, Tunabuna T, Toribio JA (2018) A retrospective study on bovine tuberculosis in cattle on Fiji: study findings and stakeholder responses. Front Vet Sci 5:270

Bouchez-Zacria M, Courcoul A, Durand B (2018) The distribution of bovine tuberculosis in cattle farms is linked to cattle trade and badger-mediated contact networks in south-western France, 2007-2015. Front Vet Sci 5:173

Brook RK, Wal EV, van Beest FM, McLachlan SM (2013) Evaluating use of cattle winter feeding areas by elk and white-tailed deer: implications for managing bovine tuberculosis transmission risk from the ground up. Prev Vet Med 108:137-147

Brooks-Pollock E, Roberts GO, Keeling MJ (2014) A dynamic model of bovine tuberculosis spread and control in Great Britain. Nature 511:228-231

Brunton LA, Prosser A, Pfeiffer DU, Downs SH (2018) Exploring the fate of cattle herds with inconclusive reactors to the tuberculin skin test. Front Vet Sci 5:228

Buddle BM, Vordermeier HM, Chambers MA, de Klerk-Lorist LM (2018) Efficacy and safety of BCG vaccine for control of tuberculosis in domestic livestock and wildlife. Front Vet Sci 5:259

Byrne AW, Allen AR, O'Brien DJ, Miller MA (2019) Bovine tuberculosis-international perspectives on epidemiology and management. Front Vet Sci 6:202

Cantlay JC, Ingram DJ, Meredith AL (2017) A review of zoonotic infection risks associated with the wild meat trade in Malaysia. EcoHealth 14:361-388

Carruth L, Roess AA, Mekonnen YT, Melaku SK, Nichter M, Salman M (2016) Zoonotic tuberculosis in Africa: challenges and ways forward. Lancet 388:2460-2461

Center for Food Security and Public Health (CSFPH) (2009). Bovine tuberculosis. Retrieved from http://www.cfsph.iastate.edu/ Factsheets/pdfs/bovine_tuberculosis.pdf. Accessed $13 \mathrm{Apr}$ 2020

Chan HHY, Mpe J (2015) A rare cause of pulmonary tuberculosis. N Z Med J 128:81-83

Chauhan AS, George MS, Lindahl J, Grace D, Kakkar M (2019) Community, system and policy level drivers of bovine tuberculosis in smallholder periurban dairy farms in India: a qualitative enquiry. BMC Public Health 19:301

Cleaveland S, Shaw DJ, Mfinanga SG, Shirima G, Kazwala RR, Eblate E, Sharp M (2007) Mycobacterium bovis in rural Tanzania: risk factors for infection in human and cattle populations. Tuberculosis (Edinb) 87:30-43

Conlan AJ, McKinley TJ, Karolemeas K, Pollock EB, Goodchild AV, Mitchell AP, Birch CP, Clifton-Hadley RS, Wood JL (2012) Estimating the hidden burden of bovine tuberculosis in Great Britain. PLoS Comput Biol 8:e1002730

Control and Prevention (CDC) (2016). Fact sheets: Tuberculin skin testing. Retrieved from https://www.cdc.gov/tb/publications/facts heetstesting/skintesting.htm. Accessed 10 May 2020

Cordova E, Gonzalo X, Boschi A, Lossa M, Robles M, Poggi S, Ambroggi M (2012) Human Mycobacterium bovis infection in Buenos Aires: epidemiology, microbiology and clinical presentation. Int J Tuberc Lung Dis 16:415-417 
Cosgrove MK, O’Brien DJ, Ramsey DS (2018) Baiting and feeding revisited: modeling factors influencing transmission of tuberculosis among deer and to cattle. Front Vet Sci 5:306

Cosivi O, Grange JM, Daborn CJ, Raviglione MC, Fujikura T, Cousins D, Robinson RA, Huchzermeyer HF, de Kantor I, Meslin FX (1998) Zoonotic tuberculosis due to Mycobacterium bovis in developing countries. Emerg Infect Dis 4:59

Cousins DV (2001) Mycobacterium bovis infection and control in domestic livestock. Rev Sci Tech 20:71-85

Cousins DV, Francis BR, Gow BL (1989) Advantages of a new agar medium in the primary isolation of Mycobacterium bovis. Vet Microbiol 20:89-95

Cross M, Heeren A, Cornicelli LJ, Fulton DC (2018) Bovine tuberculosis management in northwest Minnesota and implications of the risk information seeking and processing (RISP) model for wildlife disease management. Front Vet Sci 5:190

Dasse F, Dufour B, Duong M (2019) Guidelines for monitoring workers after occupational exposure to bovine tuberculosis. Med Mal Infect 49:563

de Klerk LM, Michel AL, Bengis RG, Kriek NP, Godfroid J (2010) BCG vaccination failed to protect yearling African buffaloes (Syncerus caffer) against experimental intratonsilar challenge with Mycobacterium bovis. Vet Immunol Immunopathol 137:84-92

de la Rua-Domenech R (2006) Human Mycobacterium bovis infection in the United Kingdom: incidence, risks, control measures and review of the zoonotic aspects of bovine tuberculosis. Tuberculosis 86:77-109

Deffontaines G, Vayr F, Rigaud E, Brenot D, Boschiroli ML, Caron V, Comolet T, Coutin P, Dasse F, Dufour B, Duong M (2019) Guidelines for monitoring workers after occupational exposure to bovine tuberculosis. Medecine et maladies infectieuses. 49(8):563-73

Duguma A, Abera S, Zewdie W, Belina D, Haro G (2017) Status of bovine tuberculosis and its zoonotic implications in Borana zone southern Ethiopia. Trop Anim Health Prod 49:445-450

Fekadu F, Beyene TJ, Beyi AF, Edao BM, Tufa TB, Woldemariyam FT, Gutema FD (2018) Risk perceptions and protective behaviors toward bovine tuberculosis among abattoir and butcher workers in Ethiopia. Front Vet Sci 5:169

Fischer EA, Van Roermund HJ, Hemerik L, Van Asseldonk MA, De Jong MC (2005) Evaluation of surveillance strategies for bovine tuberculosis (Mycobacterium bovis) using an individual based epidemiological model. Prev Vet Med 67:283-301

Garner MG, Hamilton SA (2011) Principles of epidemiological modelling. Rev Sci Tech 30:407

Gormley E, Corner LA (2018) Wild animal tuberculosis: stakeholder value systems and management of disease. Front Vet Sci 5:327

Graham J, Smith GC, Delahay RJ, Bailey T, McDonald RA, Hodgson D (2013) Multi-state modelling reveals sex-dependent transmission, progression and severity of tuberculosis in wild badgers. Epidemiol Infect 141:1429-1436

Griffin JM, Williams DH, Kelly GE, Clegg TA, O'boyle I, Collins JD, More SJ (2005) The impact of badger removal on the control of tuberculosis in cattle herds in Ireland. Prev Vet Med 67:237-266

Gumi B, Schelling E, Firdessa R, Aseffa A, Tschopp R, Yamuah L, Young D, Zinsstag J (2011) Prevalence of bovine tuberculosis in pastoral cattle herds in the Oromia region, southern Ethiopia. Trop Anim Health Prod 43:1081

Gumi B, Schelling E, Berg S, Firdessa R, Erenso G, Mekonnen W, Hailu E, Melese E, Hussein J, Aseffa A, Zinsstag J (2012) Zoonotic transmission of tuberculosis between pastoralists and their livestock in south-east Ethiopia. EcoHealth 9:139-149

Habitu T, Areda D, Muwonge A, Tessema GT, Skjerve E, Gebrehiwot T (2019) Prevalence and risk factors analysis of bovine tuberculosis in cattle raised in mixed crop-livestock farming system in Tigray region, Ethiopia. Transbound Emerg Dis 66:488-496

Hadi SA, Waters WR, Palmer M, Lyashchenko KP, Sreevatsan S (2018) Development of a multidimensional proteomic approach to detect circulating immune complexes in cattle experimentally infected with Mycobacterium bovis. Front Vet Sci 5:141

Hambolu D, Freeman J, Taddese HB (2013) Predictors of bovine TB risk behaviour amongst meat handlers in Nigeria: a crosssectional study guided by the health belief model. PLoS ONE 8:e56091

Hardstaff JL, Bulling MT, Marion G, Hutchings MR, White PC (2013) Modelling the impact of vaccination on tuberculosis in badgers. Epidemiol Infect 141:1417-1427

Huang C, Wang Y, Li X, Ren L, Zhao J, Hu Y, Zhang L, Fan G, Xu J, Gu X, Cheng Z (2020) Clinical features of patients infected with 2019 novel coronavirus in Wuhan, China. Lancet 395:497-506

Islam SS, Rumi TB, Kabir SL, van der Zanden AG, Kapur V, Rahman AA, Ward MP, Bakker D, Ross AG, Rahim Z (2020) Bovine tuberculosis prevalence and risk factors in selected districts of Bangladesh. PLoS ONE 15:e0241717

Jagielski T, Minias A, van Ingen J, Rastogi N, Brzostek A, Żaczek A, Dziadek J (2016) Methodological and clinical aspects of the molecular epidemiology of Mycobacterium tuberculosis and other mycobacteria. Clin Microbiol Rev 29:239-290

Karesh WB, Cook RA, Gilbert M, Newcomb J (2007) Implications of wildlife trade on the movement of avian influenza and other infectious diseases. J Wildl Dis 43:S55

Kazoora HB, Majalija S, Kiwanuka N, Kaneene JB (2016) Knowledge, attitudes and practices regarding risk to human infection due to Mycobacterium bovis among cattle farming communities in western Uganda. Zoonoses Public Health 63:616-623

Kemal J, Sibhat B, Abraham A, Terefe Y, Tulu KT, Welay K, Getahun N (2019) Bovine tuberculosis in eastern Ethiopia: prevalence, risk factors and its public health importance. BMC Infect Dis 19:39

Khattak I, Mushtaq MH, Ahmad MUD, Khan MS, Haider J (2016) Zoonotic tuberculosis in occupationally exposed groups in Pakistan. Occup Med (Lond) 66:371-376

Lassausaie J, Bret A, Bouapao X, Chanthavong V, Castonguay-Vanier J, Quet F, Mikota SK, Théorêt C, Buisson Y, Bouchard B (2015) Tuberculosis in Laos, who is at risk: the mahouts or their elephants? Epidemiol Infect 143:922-931

Lavelle MJ, Kay SL, Pepin KM, Grear DA, Campa H III, VerCauteren KC (2016) Evaluating wildlife-cattle contact rates to improve the understanding of dynamics of bovine tuberculosis transmission in Michigan, USA. Prev Vet Med 135:28-36

Livingstone PG, Hancox N, Nugent G, De Lisle GW (2015) Toward eradication: the effect of Mycobacterium bovis infection in wildlife on the evolution and future direction of bovine tuberculosis management in New Zealand. N Z Vet J 63:4-18

Lombardi G, Botti I, Pacciarini ML, Boniotti MB, Roncarati G, Dal Monte P (2017) Five-year surveillance of human tuberculosis caused by Mycobacterium bovis in Bologna, Italy: an underestimated problem. Epidemiol Infect 145:3035-3039

Lorente-Leal V, Liandris E, Castellanos E, Bezos J, Domínguez L, de Juan L, Romero B (2019) Validation of a real-time PCR for the detection of Mycobacterium tuberculosis complex members in bovine tissue samples. Front Vet Sci 2019:6

Luciano SA, Roess A (2020) Human zoonotic tuberculosis and livestock exposure in low-and middle-income countries: a systematic review identifying challenges in laboratory diagnosis. Zoonoses Public Health 67(2):97-111

Marie-France H, Boschiroli ML, Saegerman C (2009) Classification of worldwide bovine tuberculosis risk factors in cattle: a stratified approach. Vet Res 40:50 
McGeary A (2008) The role of Mycobacterium bovis in tuberculosis in Africa. Med J Thera Africa 2:59-63

Meiring C, van Helden PD, Goosen WJ (2018) TB control in humans and animals in south Africa: a perspective on problems and successes. Front Vet Sci 5:298

Mertoğlu A, Biçmen C, Karaarslan S, Buğdayci MH (2018) Pulmonary tuberculosis due to Mycobacterium bovis revealed by skin lesion in slaughterhouse worker. Clin Respir J 12:317-321

Müller B, Dürr S, Alonso S, Hattendorf J, Laisse CJ, Parsons SD, Van Helden PD, Zinsstag J (2013) Zoonotic Mycobacterium bovisinduced tuberculosis in humans. Emerg Infect Dis 19:899

Munyeme M, Muma JB, Munang' andu HM, Kankya C, Skjerve E, Tryland M (2010) Cattle owners' awareness of bovine tuberculosis in high and low prevalence settings of the wildlife-livestock interface areas in Zambia. BMC Vet Res 6:21

Naranjo V, Gortazar C, Vicente J, de la Fuente J (2008) Evidence of the role of European wild boar as a reservoir of Mycobacterium tuberculosis complex. Vet Microbiol 127:1-9

Nishi JS, Shury T, Elkin BT (2006) Wildlife reservoirs for bovine tuberculosis (Mycobacterium bovis) in Canada: strategies for management and research. Vet Microbiol 112:325-338

Nuru A, Mamo G, Zewude A, Mulat Y, Yitayew G, Admasu A, Medhin G, Pieper R, Ameni G (2017) Preliminary investigation of the transmission of tuberculosis between farmers and their cattle in smallholder farms in northwestern Ethiopia: a cross-sectional study. BMC Res Notes 10:31

O’Brien DJ, Schmitt SM, Fitzgerald SD, Berry DE, Hickling GJ (2006) Managing the wildlife reservoir of Mycobacterium bovis: the Michigan, USA, experience. Vet Microbiol 112:313-323

OIE (2019). Bovine tuberculosis. OIE-World Organization for Animal Health. Retrieved from http://www.oie.int/en/animal-health-inthe-world/animal-diseases/bovine-tuberculosis/. Accessed 20 Apr 2020

Olea-Popelka F, Muwonge A, Perera A, Dean AS, Mumford E, Erlacher-Vindel E, Forcella S, Silk BJ, Ditiu L, El Idrissi A, Raviglione M (2017) Zoonotic tuberculosis in human beings caused by Mycobacterium bovis - a call for action. Lancet Infect Dis 17:e21-e25

Oloya J, Opuda-Asibo J, Kazwala R, Demelash AB, Skjerve E, Lund A, Johansen TB, Djonne B (2008) Mycobacteria causing human cervical lymphadenitis in pastoral communities in the Karamoja region of Uganda. Epidemiol Infect 136:636-643

Palmer MV, Thacker TC (2018) Use of the human vaccine, Mycobacterium bovis bacillus Calmette Guérin in deer. Front Vet Sci 5:244

Perez AM, Ward MP, Charmandarián A, Ritacco V (2002) Simulation model of within-herd transmission of bovine tuberculosis in Argentine dairy herds. Prev Vet Medicine 54:361-372

Phepa PB, Chirove F, Govinder KS (2016) Modelling the role of multitransmission routes in the epidemiology of bovine tuberculosis in cattle and buffalo populations. Math Biosci 277:47-58

Radostits OM, Gay CC, Hinchcliff KW, Constable PD (2006) Diseases associated with Mycobacterium species. In: Veterinary medicine. A textbook of the diseases of cattle, horses, sheep, pigs and goats 10 ed, Edinburgh, London, New York, Oxford, Philadelphia, St Louis Sydney, Toronto. Elsevier, Amsterdam, pp 1008-1017

Rahman MM, Noor M, Islam KM, Uddin MB, Hossain FM, Zinnah MA, Mamun MA, Islam MR, Eo SK, Ashour HM (2015) Molecular diagnosis of bovine tuberculosis in bovine and human samples: implications for zoonosis. Future Microbiol 10:527-535

Ramsey DS, O'Brien DJ, Smith RW, Cosgrove MK, Schmitt SM, Rudolph BA (2016) Management of on-farm risk to livestock from bovine tuberculosis in Michigan, USA, white-tailed deer: predictions from a spatially-explicit stochastic model. Prev Vet Med 134:26-38

Raphaka K, Sánchez-Molano E, Tsairidou S, Anacleto O, Glass EJ, Woolliams JA, Doeschl-Wilson A, Banos G (2018) Impact of genetic selection for increased cattle resistance to bovine tuberculosis on disease transmission dynamics. Front Vet Sci 5:237

Ribeiro-Lima J, Carstensen M, Cornicelli L, Forester JD, Wells SJ (2017) Patterns of cattle farm visitation by white-tailed deer in relation to risk of disease transmission in a previously infected area with bovine tuberculosis in Minnesota, USA. Transbound Emerg Dis 64:1519-1529

Robinson PA (2019) Farmer and veterinarian attitudes towards the risk of zoonotic Mycobacterium bovis infection in northern Ireland. Vet Rec 185:2019

Rodríguez E, Sánchez LP, Pérez S, Herrera L, Jiménez MS, Samper S, Iglesias M (2009) Human tuberculosis due to Mycobacterium bovis and M. caprae in Spain, 2004-2007. Int J Tuberc Lung Dis 13:1536-1541

S'aidu AS, Okolocha EC, Dzikwi AA, Gamawa AA, Ibrahim S, Kwaga JK, Usman A, Maigari SA (2015) Public health implications and risk factors assessment of Mycobacterium bovis infections among abattoir personnel in Bauchi state, Nigeria. J Vet Med 2015:718193

Santos N, Almeida V, Gortázar C, Correia-Neves M (2015) Patterns of Mycobacterium tuberculosis-complex excretion and characterization of super-shedders in naturally-infected wild boar and red deer. Vet Res 46:1-10

Shrikrishna D, de la Rua-Domenech R, Smith NH, Colloff A, Coutts I (2009) Human and canine pulmonary Mycobacterium bovis infection in the same household: re-emergence of an old zoonotic threat? Thorax 64:89-91

Sichewo PR, Michel AL, Musoke J, Etter E (2019) Risk factors for zoonotic tuberculosis at the wildlife-livestock-human Interface in south Africa. Pathogens 8:101

Sichewo PR, Vander Kelen C, Thys S, Michel AL (2020) Risk practices for bovine tuberculosis transmission to cattle and livestock farming communities living at wildlife-livestock-human interface in northern KwaZulu Natal, south Africa. PLoS Negl Trop Dis 14:e007618

Sikka V, Chattu VK, Popli RK, Galwankar SC, Kelkar D, Sawicki SG, Stawicki SP, Papadimos TJ (2016) The emergence of Zika virus as a global health security threat: a review and a consensus statement of the INDUSEM Joint Working Group (JWG). J Glob Infect Dis 8:3

Silva MR, Rocha AD, Araújo FR, Fonseca-Júnior AA, Alencar AP, Suffys PN, Costa RR, Moreira MA, Guimarães MD (2018) Risk factors for human Mycobacterium bovis infections in an urban area of Brazil. Mem Inst Oswaldo Cruz 2018:113

Smith GC, Delahay RJ (2018) Modeling as a decision support tool for bovine TB control programs in wildlife. Front Vet Sci 5:276

Smith RL, Schukken YH, Lu Z, Mitchell RM, Grohn YT (2013a) Development of a model to simulate infection dynamics of Mycobacterium bovis in cattle herds in the United States. J Am Vet Med Assoc 243:411-423

Smith RL, Tauer LW, Schukken YH, Lu Z, Grohn YT (2013b) Minimization of bovine tuberculosis control costs in US dairy herds. Prev Vet Med 112:266-275

Sunder S, Lanotte P, Godreuil S, Martin C, Boschiroli ML, Besnier JM (2009) Human-to-human transmission of tuberculosis caused by Mycobacterium bovis in immunocompetent patients. J Clin Microbiol 47:1249-1251

Tebug S, Njunga GR, Chagunda MG, Mapemba JP, Awah-Ndukum J, Wiedemann S (2014) Risk, knowledge and preventive measures of smallholder dairy farmers in northern Malawi with regard to zoonotic brucellosis and bovine tuberculosis. Onderstepoort J Vet Res 81:01-06

Teppawar RN, Chaudhari SP, Moon SL, Shinde SV, Khan WA, Patil AR (2018) Zoonotic tuberculosis: a concern and strategies to combat. In: Basic biology and applications of actinobacteria. IntechOpen 
Thoen CO, LoBue PA, de Kantor I (2010) Why has zoonotic tuberculosis not received much attention? Int J Tuberc Lung Dis 14:1073-1074

Tigre W, Alemayehu G, Abetu T, Deressa B (2011) Preliminary study on public health implication of bovine tuberculosis in Jimma Town, south western Ethiopia. Glob Vet 6:369-373

Torres-Gonzalez P, Soberanis-Ramos O, Martinez-Gamboa A, ChavezMazari B, Barrios-Herrera MT, Torres-Rojas M, Cruz-Hervert LP, Garcia-Garcia L, Singh M, Gonzalez-Aguirre A, de LeonGarduño AP (2013) Prevalence of latent and active tuberculosis among dairy farm workers exposed to cattle infected by Mycobacterium bovis. PLoS Negl Trop Dis 7:2013

Tsairidou S, Allen A, Banos G, Coffey M, Anacleto O, Byrne AW, Skuce RA, Glass EJ, Woolliams JA, Doeschl-Wilson AB (2018) Can we breed cattle for lower bovine TB infectivity? Front Vet Sci 5:310

Tsegaye W, Aseffa A, Mache A, Mengistu Y, Stefan B, Ameni G (2010) Conventional and molecular epidemiology of bovine tuberculosis in dairy farms in Addis Ababa city, the capital of Ethiopia. J Appl Res Vet Med 8:143

Twomey DF, Higgins RJ, Worth DR, Okker M, Gover K, Nabb EJ, Speirs G (2010) Cutaneous TB caused by Mycobacterium bovis in a veterinary surgeon following exposure to a tuberculous alpaca (Vicugna pacos). Vet Rec 166:175-177

Ullah A, Khattak US, Ayaz S, Qureshi MS (2018) An emerging zoonosis of bovine tuberculosis-a neglected zoonotic disease (NZD) in work-related occupational groups in Pakistan. J Microb Pathog 2:105

Vayr F, Martin-Blondel G, Savall F, Soulat JM, Deffontaines G, Herin F (2018) Occupational exposure to human Mycobacterium bovis infection: a systematic review. PLoS Negl Trop Dis 12:e0006208

VerCauteren KC, Lavelle MJ, Campa H III (2018) Persistent spillback of bovine tuberculosis from white-tailed deer to cattle in Michigan, USA: status, strategies, and needs. Front Vet Sci 5:301

Wedlock DN, Skinner MA, de Lisle GW, Buddle BM (2002) Control of Mycobacterium bovis infections and the risk to human populations. Microbes Infect 4:471-480

White PC, Lewis AJ, Harris S (1997) Fertility control as a means of controlling bovine tuberculosis in badger (Meles meles) populations in south-west England: predictions from a spatial stochastic simulation model. Proc R Soc B 264:1737-1747

Wilkins MJ, Bartlett PC, Frawley B, O'Brien DJ, Miller CE, Boulton ML (2003) Mycobacterium bovis (bovine TB) exposure as a recreational risk for hunters: results of a Michigan hunter survey, 2001. Int J Tuberc Lung Dis 7:1001-1019

Wilkins MJ, Meyerson J, Bartlett PC, Spieldenner SL, Berry DE, Mosher LB, Kaneene JB, Robinson-Dunn B, Stobierski MG, Boulton ML (2008) Human Mycobacterium bovis infection and bovine tuberculosis outbreak, Michigan, 1994-2007. Emerg Infect Dis 14:657

Wilkins MJ, Bartlett PC, Judge LJ, Erskine RJ, Boulton ML, Kaneene JB (2009) Veterinarian injuries associated with bovine TB testing livestock in Michigan, 2001. Prev Vet Med 89:185-190

Willeberg P, Paisley LG, Lind P (2011a) Epidemiological models to support animal disease surveillance activities. Rev Sci Tech 30:603-614

Willeberg P, Paisley LG, Lind P (2011b) The world organisation for animal health and epidemiological modelling: background and objectives. Rev Sci Tech 30:391

World Health Organization (WHO) (2016). Global tuberculosis report 2016. Retrieved from http://www.who.int/tb/publications/global_ report/en/. Accessed 29 April 2020

World Organization for Animal Health (OIE) (2015). Bovine tuberculosis. Available at https://www.oie.int/fileadmin/Home/eng/ Health_standards/tahm/3.04.06_BOVINE_TB.pdf. Accessed 5 May 2020

World Organization for Animal Health (OIE), World Health Organization (WHO), Food and Agricultural Organization of the United Nations (FAO) (2017). Roadmap for zoonotic tuberculosis. Retrieved from http://www.oie.int/fileadmin/Home/eng/Our_ scientific. Accessed 25 Apr 2020

Publisher's Note Springer Nature remains neutral with regard to jurisdictional claims in published maps and institutional affiliations. 